\title{
Experiencing Venus: Clues to the Origin, Evolution, and Chemistry of Terrestrial Planets via In-Situ Exploration of our Sister World
}

\author{
Kevin H. Baines ${ }^{1}$, Sushil K. Atreya ${ }^{2}$, Robert W. Carlson ${ }^{1}$, David Crisp ${ }^{1}$, \\ David Grinspoon ${ }^{3}$, Christopher T. Russell ${ }^{4}$, Gerald Schubert ${ }^{5}$, and Kevin Zahnle ${ }^{6}$
}

We review the current state of knowledge of (1) the origin and evolution of Venus and (2) the photochemical and thermochemical processes occurring in the middle and lower atmosphere there. For each, we review the promise of on-going and planned orbital observations by ESA's Venus Express and Japan's Venus Climate Orbiter missions. We review the need for future in-situ measurements for understanding Venus origin and evolution and present-day chemistry, and the implications for understanding the origin and history of the Earth and other bodies in the inner solar system, as well as for understanding terrestrial planets in other solar systems. We prioritize the goals remaining in the post Venus Express era, based on the Decadal Survey (National Research Council, 2003). Using past experience with Pioneer Venus, VEGAs, Veneras, and, most recently, Venus Express as guides, we suggest appropriate techniques and measurements to address these fundamental science issues.

\section{INTRODUCTION}

The exploration of Venus is experiencing a renaissance as space agencies in Europe and Japan develop, launch, and execute missions to Earth's sister planet. On April 11, 2006,

${ }^{1}$ Jet Propulsion Laboratory, California Institute of Technology, Pasadena, California, USA.

2 Department of Atmospheric, Oceanic, and Space Sciences, The University of Michigan, Ann Arbor, Michigan, USA.

${ }^{3}$ Department of Space Sciences, Denver Museum of Nature and Science, Denver, Colorado, USA.

${ }^{4}$ Institute of Geophysics and Planetary Physics, University of California, Los Angeles, California, USA.

${ }^{5}$ Dept. of Earth and Space Sciences, Institute of Geophysics and Planetary Physics, University of California, Los Angeles, California, USA.

${ }^{6}$ NASA/Ames Research Center, Moffett Field, California, USA.

Exploring Venus as a Terrestrial Planet

Geophysical Monograph Series 176

Copyright 2007 by the American Geophysical Union. 10.1029/176GM11 the Venus Express orbiter was placed into orbit about Venus by the European Space Agency. As a rapid-development follow-on to Mars Express, this relatively small $(\sim \$ 300 \mathrm{M})$, fast $(\sim 3$ years from selection to launch) mission uses the MarsExpress-based spacecraft bus and an array of instruments inherited from the Rosetta and Mars Express missions to provide the most systematic, thorough and complete investigation of Venus's complex atmosphere yet achieved.

During its 16-month prime science mission, which began in June 2006, the Venus Express orbiter circles the planet daily in a polar elliptical orbit, regularly imaging and sounding the planet from the upper atmosphere, through its various middlelevel cloud layers, down to the depths of the lower atmosphere and surface (c.f., Baines et al., 2006; Taylor, 2006; and Titov et al., 2006 for mission summaries). A variety of UV, visible, near-IR, mid-IR, and radio techniques map clouds and chemically-reactive species throughout the atmosphere, enabling a new understanding of Venus's active photo- and thermochemical processes. In addition the nadir-viewing mapping capabilities of the Visible and Infrared Thermal Imaging Spectrometer (VIRTIS) provide the potential for mapping 
near-IR surface properties and a search for outgassing and thermal emissions indicative of active volcanism. The Venus Radio experiment (VeRa) periodically acquires detailed radio occultation profiles down to the $\sim 36 \mathrm{~km}$ level. It also probes the surface in its bistatic radar mode, using Earth-based radio telescopes to receive the echoes of VeRa signals directed at the surface. In the upper reaches of the atmosphere, a sophisticated fields and particles experiment—known as Analyser of Space Plasmas and Energetic Atoms (ASPERA) - measures the solar wind and the flux of ionized species leaving Venus, thereby elucidating the present-day rate of loss of hydrogen and other species from the planet. Currently, after six months in orbit, savings in the fuel needed to maintain a stable orbit suggests that the mission is on course for a planned 16-month mission extension, with potential for a similar second extension, thus providing up to ten Venus solar days of on-orbit observations by June, 2010.

As currently planned, in that same year, 2010, the Japan Aerospace Exploration Agency (JAXA) will launch the Venus Climate Orbiter (VCO). Its suite of four cameras will repeatedly image the planet's cloud systems at two levels and surface from an equatorial orbit. Together, as currently planned, Venus Express and VCO will globally map both the observed winds and theoretically-derived equilibrium wind field of Venus throughout more than a dozen Venus days, thereby providing information extremely useful for determining the nature of dynamical processes powering the planet's baffling world-wide super-rotating zonal winds.

Such missions are also providing fundamental new data on the nature of the planet's surface. In particular, nearinfrared maps in the $0.9-1.2-\mu \mathrm{m}$ spectral range by VIRTIS on Venus Express are beginning to reveal in detail the spatial variability of thermal surface emission, due to variations in elevation and surface composition. As first discovered by Allen (1984) in groundbased observations and further revealed by the Galileo and Cassini flybys (Carlson et al., 1991; Baines et al., 2000), several useful spectral "windows" between $\mathrm{CO}_{2}$ bands exist in the 0.9-1.2- $\mu \mathrm{m}$ range which allow thermal emission from Venus's hot ( $740 \mathrm{~K})$ surface to be readily viewed under nighttime conditions wherein the strong glint from sunlit clouds is suppressed. The adiabatic lapse rate of $8 \mathrm{~K}$ per $\mathrm{km}$ altitude ensures dramatic variations of surface thermal flux with elevation, as previously demonstrated by the flyby mapping of the Near Infrared Mapping Spectrometer (NIMS) on-board the Galileo spacecraft enroute to Jupiter (Carlson et al., 1991, 1993a) and by ground-based observations (Lecacheux et al., 1993; Meadows and Crisp, 1996). Venus Express and VCO will exploit these windows to globally map surface properties at a spatial-resolution of $\sim 50 \mathrm{~km}$, as limited by the diffusion of upwelling radiation caused by atmospheric scattering. Incorporation of known elevations from Magellan and Pioneer Venus Orbiter radar measurements in the analysis is likely to enable the separation of elevation effects from effects due to variations in the emissivity of surface materials, thus providing meaningful constraints on the distribution of surface materials over the globe (Hashimoto and Sugita, 2003). In addition, both missions plan to conduct searches for active volcanism by watching for unusual spatial and/or temporal anomalies in surface brightness (Hashimoto and Imamura, 2001) or low-altitude abundances of volcanic gases (such as $\mathrm{SO}_{2}$ ). The discovery and characterization of active volcanism - the first for any terrestrial planet beyond Earth - would provide a fundamental key to understanding the planet's geology, interior, atmospheric evolution, and climate, as well as provide a deeper perspective on the geologic nature of terrestrial planets throughout the universe.

Additional impetus for the new renaissance in Venus exploration has recently come from the U. S. planetary science community. In 2003, under the auspices of the Space Studies Board of the National Research Council, the community's Solar System Exploration Survey (SSES) produced its report "New Frontiers in the Solar System: An Integrated Exploration Strategy" (National Research Council, 2003). A major finding of this "Decadal Survey", as this report is informally known, is the need for direct, in-situ sampling of Venus, of both its atmosphere and surface. Despite the intense orbital scrutiny provided by Venus Express and VCO, there are major questions dealing with the evolution and chemistry of the planet, as well as its dynamics, that can only be appropriately addressed via in-situ measurements. These include measurements of the abundance of inert noble gases and their isotopes - which are readily accessible and bear the scars of Venus' origin and evolution - as well as a wide range of chemically-active gases important for understanding Venus' present-day meteorology and chemical cycles. None of the noble gases and just a handful of reactive gases can be measured remotely from orbiting spacecraft. Thus, as recognized by the Decadal Survey, in-situ atmospheric sampling is the essential next step. Many measurements can only be made by in situ sampling, and in situ sampling provides "ground truth" for the gases sounded remotely by Venus Express, VCO, and ground-based spectroscopy.

In this paper, based largely on the findings of the Decadal Survey (NRC, 2003), we review the need for in-situ sampling of the Venus atmosphere, concentrating on the scientific objectives that can be met by relatively small missions, such as may be affordable under NASA's Discovery Program. We then expand the discussion to cover all of the high-priority Venus science objectives identified by the Decadal Survey, and summarize viable mission architectures that can accomplish each of these objectives. 


\section{THE NEED FOR IN-SITU EXPLORATION OF VENUS}

More than any other pairing of terrestrial planets, Venus and Earth are virtual twins. To within $20 \%$, they have the same radius, volume, mass, and gravity. They also have similar bulk compositions. At the tops of their major clouds, they also have similar temperatures and pressures. Furthermore, based on a simple, first-order analysis of the solar flux and the deposition of solar energy as determined from their respective solar distances and global geometric albedos, they also have the same effective temperature.

Yet, Venus does not follow our expectations. Its mean surface temperature is nearly 2.6 times that of Earth $(740 \mathrm{~K}$ vs $288 \mathrm{~K}$ terrestrial mean). Despite a rate of rotation more than 100 times slower than Earth's, its solar-powered 1-barlevel winds flow globally at an average speed greater than the sustained speed of the Earth's mightiest jet streams. Both the surface and atmosphere of Venus are exceedingly dry ( $\sim 30$ ppm water vs $\sim 30,000$ ppm in Earth's atmosphere). Its ubiquitous clouds are composed not of water, but of sulfuric acid, indicative of a complex cycle of sulfur-based corrosive chemistry throughout the planet's extensive 94-bar thick atmosphere and surface.

Thus, despite their bulk similarities, Venus is not at all like Earth. It is an alien place, seemingly inhospitable to the types of long-duration, in-situ exploration thus far accomplished on Earth, the Moon and Mars. The strange, alien nature of Venus is linked to it history. Due to both cataclysmic and gradual events in the past, Venus proceeded along a distinctly different evolutionary path than Earth. Answering fundamental questions of Venus's history - as can only be done with in-situ sampling of ancient materials imbedded within the planet's atmosphere and surface-will undoubtedly reveal key lessons for the past, present, and future of Earth's environment and climate, as well as all terrestrial planets.

As noted by the Decadal Survey (NRC, 2003), direct sampling of atmospheric constituents is key to understanding how the planet formed and evolved as well as understanding the complex chemistry coupling the surface and atmosphere. In particular, the heavy noble gas elements xenon, krypton, and argon and their isotopes provide an accessible historical record of ancient events, pertinent to planetary formation and early evolutionary processes. Radiogenic isotopes of helium, argon and xenon also provide dating constraints on geologic processes that over the eons may have delivered materials from the deep interior to the surface.

The remarkable property that renders the noble gases and their isotopes so valuable in determining ancient events is their stability against chemical alterations. Unfortunately, this stability against chemical reactions manifests itself as well in an absolute stability against photonic interactions. Thus no spectral features exist. Consequently, the abundances of these elements cannot be readily assessed by remote sensing techniques, as from the Venus Express orbiter. Only in-situ sampling can do it.

Beyond sampling of noble gases for understanding the historical record, the sampling of the plethora of other constituents present in Venus's atmosphere is extremely valuable for understanding how Venus works today. Precise, simultaneous sampling of a variety of sulfur-bearing constituents and related molecules over a wide range of altitudes, latitudes, longitudes, and time can yield important insights into cloud formation/dissipation, the sulfur cycle, meteorology, and climate. Such insights can be significantly enhanced by simultaneous measurements of dynamically related processes such as pressure and temperature, vertical and horizontal winds, and cloud properties (e,g., particle sizes and distributions). Such precise sampling at specific altitudes can only be achieved in-situ. Ultimately-since atmospheric sulfur is the product of either volcanism and/or tectonic activity- these atmospheric measurements bear directly on understanding the current state and recent history of volcanic and geologic processes.

\section{THE EVOLUTION OF VENUS: EVIDENCE FROM BULK PROPERTIES AND RADAR IMAGERY}

The similarity of Venus and Earth in size, mass and distance from the Sun suggests that Venus and Earth had similar early histories of accretion and internal differentiation. Nevertheless, Venus and Earth proceeded along different evolutionary paths, as is evident from a comparison of the planets' satellites, magnetic fields, tectonics, rotational states, and atmospheres.

Venus does not have a moon, but the reason for this is not understood. Of course, it could simply be by chance, but Venus was likely subject to major impacts in its early evolution. Such an impact with Earth apparently produced its moon. The lack of a Venusian moon has been attributed to inward spiraling and collision with the planet of a satellite that might once have existed. It has also been explained by satellite escape. However, neither explanation is plausible. The inward spiraling scenario is unlikely since post giant impact rotation and orbital motion tend to be in the same sense, contrary to the direction of Venus's rotational spin today. The escape scenario is unlikely for reasonable $Q$ values and moon masses (Stevenson, 2006).

Venus does not have an intrinsic magnetic field (Russell, 1980; Phillips and Russell, 1987; Donahue and Russell 1997, Nimmo, 2002), a fact that has at least two reasonable expla- 
nations both connected with the planet's thermal evolution. On the assumption that Venus was initially hot and differentiated, it has long possessed a liquid metallic core. Hence it is possible that the planet had an early dynamo-generated magnetic field. Whether such a field existed and persisted for some length of time depends on the core cooling history. The rate of core cooling, controlled by the ability of the mantle to extract heat from the core, must be sufficient to support convection and dynamo action in the core. This suggests one explanation for the absence of a present day magnetic field. Venus underwent a transition during its evolution from efficient core cooling by a plate tectonic-like mode of mantle convection to an inefficient mode of stagnant or sluggish lid mantle convection that was unable to cool the core rapidly enough to support dynamo activity. Nimmo and Stevenson (2000) have proposed a similar explanation for the absence of a present day Martian magnetic field. A potential test of the existence of an ancient dynamo is the detection of remanent magnetization from this epoch. However the high surface temperature on Venus makes this detection unlikely but not necessarily impossible.

A second explanation for the lack of a magnetic field is also related to inefficient core cooling by the mantle and the lower pressure in Venus' core compared with the pressure in Earth's core due to Venus's smaller mass. It is possible that Venus's core has not yet cooled sufficiently to initiate inner core growth, but has cooled enough to prevent the operation of a purely thermally driven dynamo (Stevenson et al., 1983). It is believed that dynamo action in Earth's core is substantially facilitated by compositional convection driven by inner core solidification. The absence of plate tectonics on Venus is consistent with a style of mantle convection that is inefficient in cooling its core. That Venus might have a liquid core at present is indicated by Doppler radio tracking data of the Magellan and Pioneer Venus spacecraft which have provided an estimate of the tidal Love number $\mathrm{k}_{2}$ (Sjogren et al., 1997). The Love number $\mathrm{k}_{2}$ is determined from the time variations in the gravitational coefficients $\mathrm{C}_{22}$ and $\mathrm{S}_{22}$ at the solar period. Konopliv and Yoder (1996) have found $\mathrm{k}_{2}=0.295 \pm 0.066$, a value consistent with a liquid core (Yoder, 1997).

Magellan radar global imagery strongly suggests that Venus lacks plate tectonics, a conclusion supported by the almost total absence of a global system of ridges and trenches similar to those found in the oceans on Earth (Kaula and Phillips, 1981). At the present time, Venus is a one-plate planet. Mantle convection in Venus must therefore be of the sluggish or stagnant lid mode, a relatively inefficient way to cool the core (Schubert et al. 1997). The absence of plate tectonics on Venus could have something to do with the planet's lack of water. If Venus had water early in its history it could have had a style of mantle convection similar to plate tectonics. With a plate tectonic-like mantle convection regime there might also have been a magnetic field. It is therefore possible that atmospheric evolution, by way of an intense greenhouse effect and loss of water, had a controlling influence on the evolution of the entire solid planet, shutting down plate tectonics, core cooling, and dynamo action. The atmosphere, a relatively minor part of Venus by mass, could have controlled the thermal and rotational history of the entire planet.

The absence of plate tectonics on Venus and its implications for the relatively inefficient removal of heat from the planet's interior could account for a hypothesized major event in Venus's evolution. It has been proposed that the relatively young age of Venus's surface (about 500-800 Myr according to studies of the impact crater population, McKinnon et al. 1997, Herrick et al. 1997) was set in a global volcanic resurfacing event and that relatively little volcanism has occurred since (Schaber et al. 1992, Basilevsky et al., 1997). The resurfacing event could be the means by which Venus expels its heat. One way this could happen is by the global foundering of a thick, relatively cold and heavy lithosphere and its replacement by the relatively hot underlying mantle. Such events might have occurred episodically throughout Venus's history. Between such events the lithosphere would thicken but Venus would have no efficient way, like plate tectonics on Earth, to expel its heat. Instead the heat building up in the interior during the quiescent period would be lost in the mantle overturn when the lithosphere thickened enough to become gravitationally unstable. The initiation of such an event might be evident today on Venus's surface in the form of large coronae. McKenzie et al. (1992) and Sandwell and Schubert (1992a, b) have argued that the perimeters of several large coronae on Venus, specifically Artemis, Latona, and Eithinoa, resemble terrestrial subduction zones in both planform and topography. Artemis chasma has a radius of curvature similar to that of the South Sandwich subduction zone on the Earth. Sandwell and Schubert (1992a) proposed that the large coronae are incipient circular subduction zones. The foundering lithosphere is replaced by ascending hot mantle in a manner similar to back-arc spreading on the Earth. A consequence of a global resurfacing event would be the emplacement of mantle volatiles into the atmosphere. Of course, the resurfacing event and its consequences do not necessarily have to occur abruptly on the geologic time scale, but could take place over several hundred million years or even longer.

Although Venus is a one-plate planet at present, Magellan radar imagery has shown that there are tectonic features on its surface that resemble major tectonic features on Earth. Beta Regio, a volcanic highland, has many of the features 
of a continental rift on Earth. It has a domal structure with a diameter of about $2000 \mathrm{~km}$ and a swell amplitude of about $2 \mathrm{~km}$. It has a well defined central rift valley with a depth of $1-2 \mathrm{~km}$ and there is some evidence for a three-armed planform (aulacogen). Alta, Eistla, and Bell Regiones have similar rift zone characteristics (Grimm and Phillips, 1992; Senske et al., 1992). Aphrodite Terra with a length of some $1500 \mathrm{~km}$ is reminiscent of major continental collision zones on Earth, such as the mountain belt that extends from the Alps to the Himalayas. Ishtar Terra is a region of elevated topography with a horizontal scale of 2000-3000 km. A major feature is Lakshmi Planum, which is an elevated plateau similar to Tibet with a mean elevation of about $4 \mathrm{~km}$. This plateau is surrounded by linear mountain belts-Akna, Danu, Freyja, and Maxwell Montes - which reach elevations of $10 \mathrm{~km}$, similar in scale and height to the Himalayas (Kaula et al., 1997).

Venus rotates in a retrograde sense with a spin period of 243 days. How this spin state came about is unknown, but it might be maintained by a balance between solid body tides raised on Venus by the Sun's gravity and a frictional torque on the solid planet exerted by the super-rotating atmosphere (Gold and Soter 1969, 1979, Kundt 1977, Ingersoll and Dobrovolskis 1978, Dobrovolskis and Ingersoll 1980). Such a balance would require the source of atmospheric angular momentum to be the solar torque on the atmospheric thermal tide. Alternatively, the super-rotating atmosphere could derive its angular momentum from the solid planet, resulting in a secular variation in the planet's spin. The angular momentum of Venus' atmosphere is $1.6 \times 10^{-3}$ of the solid body angular momentum, making the possibility of angular momentum exchanges, both long term and short term, highly significant for both the atmosphere and solid planet; these momentum exchanges could be manifest in measurable length of day variations (Schubert, 1983).

As noted earlier, the atmosphere of Venus bears no resemblance to Earth's atmosphere. The atmosphere of Venus is almost 100 times as massive as Earth's, with extreme surface pressure and temperature conditions: about 94 bars and $740 \mathrm{~K}$ (Seiff 1983). Venus's atmosphere is predominantly $\mathrm{CO}_{2}$, roughly equivalent to the amount of $\mathrm{CO}_{2}$ tied up in carbonate rocks on Earth, and is extremely dry, with about $30 \mathrm{ppm}$ of $\mathrm{H}_{2} \mathrm{O}$, corresponding to $\sim 10^{-3}$ of the water content of Earth's atmosphere. Consequently, Venus's ubiquitous cloud system is comprised not of water, but of sulfuric acid, indicative of a complex cycle of sulfur-based corrosive chemistry throughout the atmosphere. How did the atmosphere evolve to its present state if it was initially similar to Earth's atmosphere with a substantial complement of water? A strong possibility is that an intense greenhouse effect led to the vaporization of all water on early Venus, followed by photodissociation of the water vapor at high altitudes and the escape of the released hydrogen into space. Without liquid water on its surface, $\mathrm{CO}_{2}$ could then not be sequestered in the surface rocks. This change in Venus's atmosphere, if it occurred, would have triggered changes in the planet reaching all the way to its core. The loss of water would stop plate tectonics. This would have changed the style of mantle convection, slowed the rate of core cooling, and turned off the magnetic field.

If Venus once had an intrinsic magnetic field, it is possible, though perhaps not very likely, that some remanent magnetization of the crust might have survived to the present. However, while the surface temperature of Venus is below the blocking temperature of common minerals, the prolonged exposure of rocks to high temperature over hundreds of millions of years or longer would tend to destroy their magnetic domains.

How can these evolutionary story lines be checked? One way, as discussed in detail below, is the measurement of minor constituents and their isotopic compositions.

\section{NOBLE GASES: THE KEY TO THE PAST}

Since noble gases are thermochemically and photochemically inert, they provide a variety of keys to unlocking the history of planets, including Earth and Venus. Non-radiogenic noble gas isotopes preserve records of the materials that originally formed the planets and the evolution of their atmospheres. In contrast, radiogenic components are the daughters of parent molecules. Because noble gases are enormously depleted in planets compared to other elements, radiogenic noble gas isotopes produced by decay of even rare radioactive parents can be relatively abundant and readily measured. Consequently, the abundances of radiogenic isotopes provide a variety of clocks for understanding the formation and evolutionary history of Venus and Earth, as well as other planetary bodies such as the Moon and Mars. How these planets initially formed, the cataclysmic events in their early histories and the nature of major geologic events throughout their evolution are examples of basic insights potentially provided through accurate sampling of noble gases and their isotopes (cf., Plate 1). Accurate measurements for Venus, in particular, would help elucidate the history of the entire inner Solar System, as we now discuss.

\section{In the Beginning: The Origin of Venus as Revealed by Neon, Xenon, Krypton and Argon}

Neon Isotopic Ratios: Earth and Venus as Fraternal Twins? On Earth, neon in the atmosphere has an isotopic composition that is mass-fractionated with respect to neon 


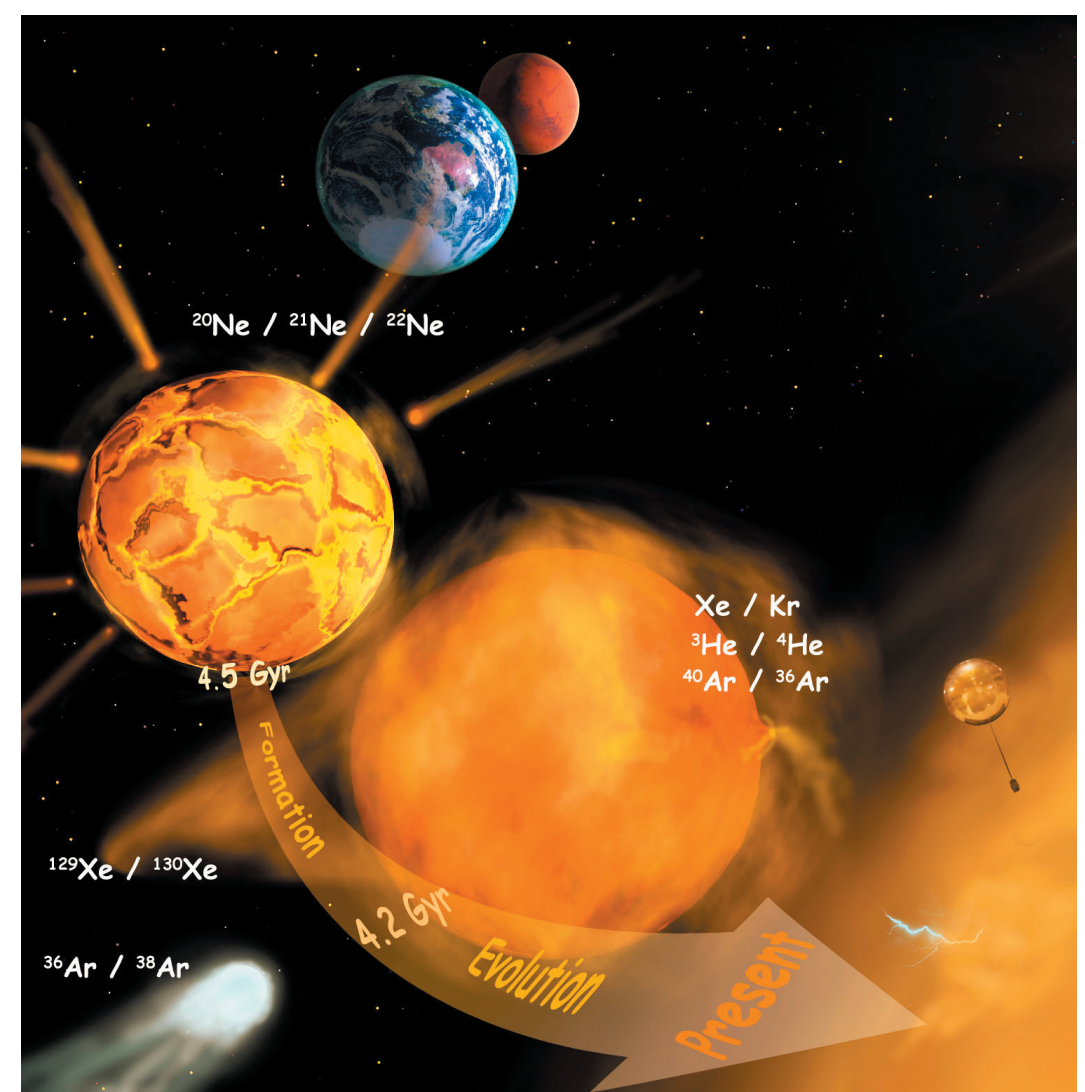

Plate 1. Clues to the formation and early history of the terrestrial planets are locked in the abundances of noble gases and their isotopes on Venus. The abundances of xenon, krypton and other tracers of Venus's past await in-situ atmospheric sampling by a future mission, such as by a probe or balloon-borne science station, depicted on the right.

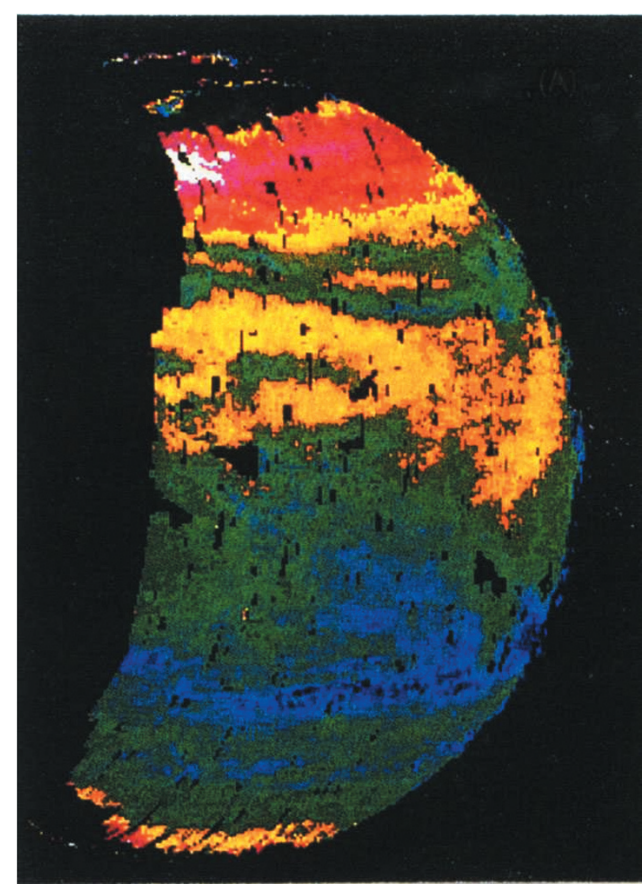

Plate 2. Near -Infrared Mapping Spectrometer (NIMS) map of hemispherical asymmetry in Venus cloud particle distribution: Light-greycolored aerosols in the north are 10 times larger by volume than dark-colored particles in the south (Carlson et al., 1993b). 
in the mantle, with the atmosphere incorporating a larger proportion of the heavier neon isotopes. This suggests that neon has escaped from Earth's atmosphere. Further evidence of neon escape comes from the $\sim 100$ times less neon/argon ratio seen on Earth today compared to parent nebular values. Sasaki and Nakazawa (1988) have modeled both the bulk and fractionated neon, and have shown that, in principle, Earth could lose the neon from a solar nebula composition atmosphere while generating the observed amount of fractionation.

Since neon has three stable isotopes, in principle we can tell whether neon on Earth is related to that on Venus by mass fractionation of a common ancient neon located in a common part of the parent nebula, or whether Venus and Earth accreted their neon from different sources. Specifically, if the $\left({ }^{22} \mathrm{Ne} /{ }^{20} \mathrm{Ne},{ }^{21} \mathrm{Ne} /{ }^{20} \mathrm{Ne}\right)$ ratios for Venus and Earth fall on the mass fractionation line predicted by escape processes, it would imply the two planets began as neon twins, sharing the same source of noble gases (and perhaps other volatiles), and then evolved via escape to the present-day ratios. On the other hand, if the observed ratios don't both fall on the fractionation/escape line, then the two planets likely accreted their neons from disparate sources, thus indicating that a variety of formation processes and realms in the parent nebulae helped to create the inner planets. Such information has broad implications as well for the formation of extrasolar planets within other parent nebulae.

Xenon and Krypton: Coded Messages from Ancient Cataclysms. Xenon (Xe) is of special interest because, on both Earth and Mars, its abundance and isotopic composition do not closely resemble any known solar system source materials, which together point to major events in the early histories of planets. There are three major differences. First, xenon's nine non-radiogenic isotopes are strongly mass fractionated (with a gradient of $\sim 4 \%$ per amu) compared to the solar wind or any of its plausible solar system sources (Pepin, 1991). Second, the bulk abundance of non-radiogenic xenon is depleted with respect to krypton $(\mathrm{Kr})$. The depletion is a factor of $\sim 20$ when comparing Earth to typical chondritic meteorites. The strong mass fractionation of the non-radiogenic isotopes implies that what we see today on Earth and Mars are ragged remnants of atmospheric escape that occurred during the formation processes of these planets.

The third major difference involves radiogenic isotopes of xenon, which are also markedly depleted compared to the measured abundances of their radioactive parents in primitive Solar System materials. The bulk and radiogenic component depletions together add up to the "missing Xe problem." The important point is that, because xenon is the heaviest gas in the atmosphere, xenon loss implies that escape processes affected all the gases of the atmosphere. All three xenon abundance characteristics indicate a variety of cataclysmic events on both Earth and Mars late in the planetary formation process.

Important sources of radiogenic xenon are the decay of short-lived isotopes of iodine $\left({ }^{129} \mathrm{I}\right.$, half-life $\left.15.7 \mathrm{Myr}\right)$ and plutonium $\left({ }^{244} \mathrm{Pu}\right.$, half-life $\left.82 \mathrm{Myr}\right)$. Iodine produces just a single isotope, ${ }^{129} \mathrm{Xe}$; thus, iodine-decay-produced xenon is relatively easy to measure. Some $7 \%$ of Earth's ${ }^{129} \mathrm{Xe}$ is from ${ }^{129} \mathrm{I}$, while fully $50 \%$ of the ${ }^{129} \mathrm{Xe}$ in Mars's atmosphere is from ${ }^{129} \mathrm{I}$. Yet these abundances are much less than expected for planetary atmospheres if there had been no escape. Earth, for example, retains only $\sim 0.8 \%$ of its cosmic complement of ${ }^{129} \mathrm{I}$-generated ${ }^{129} \mathrm{Xe}$ produced within its accreted material, while Mars retains just 0.1\% (Porcelli and Pepin, 2000; Ozima and Podosek, 2002). In other words, more than $99 \%$ of the ${ }^{129} \mathrm{Xe}$ produced from the radioactive decay of iodine has been lost from Earth and Mars. Given ${ }^{129}$ I's 15.7 million year half-life, much of this escape must have occurred from planet-sized bodies during accretion. But, as well, its half-life is long enough that much of it must have also been lost after Earth was a planet, and some of it after the Moonforming impact. The degree to which Venus resembles the other terrestrial planets provides a measure of the similarity of planetary evolution during the time of giant impacts in the planet formation process.

Somewhat similar arguments apply to radiogenic xenon born of spontaneous fission of ${ }^{244} \mathrm{Pu}$. Plutonium is especially important because its 82 million year half-life probes the early evolution of the planet after accretion. Fission xenon has been detected in Earth's mantle, and there appears to be some in Earth's atmosphere. How much is uncertain, but the upper limit is about $20 \%$ of what Earth's primordial plutonium should have generated. Whatever process removed fissogenic xenon from the atmosphere (or prevented its venting into the atmosphere) was one that took place some 200 million years after Earth formed.

Four general scenarios can be invoked to explain the loss and fractionation of xenon. In one scenario, the terrestrial planets experienced different degrees of atmospheric blowoff. The cause was hydrogen escape driven by solar EUV radiation more than one hundred times stronger than today. As the hydrogen escaped, it dragged other gases with it, especially the lighter isotopes of the noble gases. What remained behind became isotopically heavy (Zahnle and Kasting, 1986; Hunten et al.; 1987; Sasaki and Nakazawa, 1988; Zahnle et al., 1990a; Pepin, 1991). A variant attributes escape to the Moon-forming impact (Pepin, 1997). In either of Pepin's $(1991,1997)$ models, escape was followed by degassing of the lighter noble gases from the interior, thus replenishing Earth's atmosphere with the amounts of lighter 
noble gases seen today. In either model there is relatively little escape from Venus, so that Venus holds a larger and less altered portion of its original complement.

A related model ascribes most of the xenon loss to atmospheric erosion caused by impacts during accretion. Impact erosion is expected to treat all gases equally, so that the only fractionation is between gases and condensed materials. Thus one expects impact erosion to expel noble gases much more readily than water. This may have been the means by which planets lost their radiogenic xenon. But impact erosion cannot account for the mass fractionation of xenon's isotopes. Thus impact erosion is not the whole story.

In a third scenario, the xenon isotopic pattern seen on Earth today is the signature of a common external source such as large planetesimals or comets. This hypothesis then requires that much of Earth's primordial xenon-including radiogenic products from plutonium and iodine decay-be sequestered deep in the planet's interior. Large planetesimals can fractionate isotopes by gravitational segregation (Ozima and Podosek, 2002; Zahnle et al., 1990b). Extremely porous cold bodies immersed in nebular gases, such as large comets, are required. Comets are a possible source primarily because their compositional make-up vis-a-vis noble elements is not well-constrained. Formed in the cold reaches of the outer solar system, comets could perhaps incorporate xenon isotopic signatures substantially different from those in the inner nebula. Such bodies could then deliver these signatures to the Earth (and likely other nearby bodies) to produce the enigmatic isotopic xenon distribution seen today.

A fourth scenario invokes properties unique to xenon among the noble gases. An example is that Xe alone among the noble gases is easier to ionize than hydrogen. Consequently, when embedded in a partially ionized hydrogen wind that is flowing upward to space, xenon tends to be present as an ion while the other noble gases are neutral. The Coulomb force between xenon ions and protons is big and thus xenon ions are relatively easily dragged away by the escaping wind, while the lighter noble gases, being neutral, go nowhere. This describes a variant on atmospheric blowoff that leaves the bulk of the atmosphere intact while allowing xenon to escape.

Sampling xenon and its isotopes on Venus can help resolve which mechanism is responsible for the xenon signature observed on Earth, elucidating a crucial part of Earth's early history. A common fractionation pattern would indicate a common source of xenon isotopes. This would strengthen the hypothesis that comets or large planetesimals were a major source of volatiles throughout the inner solar system. On the other hand, the solar EUV blowoff theory would be strengthened if the fractionation of xenon isotopes in Venus were found to be different than found on Earth, since the power of hydrogen blowoff might be expected to differ between Venus and Earth. The Earth-blowoff hypothesis would be strengthened further if radiogenic ${ }^{129} \mathrm{Xe}$ were found in large amounts on Venus, rather than the small amounts $(\sim 7 \%)$ found on Earth, thus indicating that a blowoff took out virtually all of the iodine-generated xenon from the early terrestrial atmosphere. Abundant radiogenic xenon on Venus would also indicate that impact erosion was relatively unimportant. Unfortunately, no isotopic abundance information for Venus exists today. Only a crude bulk Xe abundance upper limit of $<4 \mathrm{ppb}$ has been assigned (Donahue and Russell, 1997).

Isotopic measurements of Venus's xenon also provide a fundamental test of the "U-Xe" hypothesis for Earth, which asserts that terrestrial xenon is the sum of mass fractionated primordial U-Xe and a small dose of heavy isotopes obtained from the spontaneous fission of ${ }^{244} \mathrm{Pu}$. The hypothetical primordial U-Xe is depleted in heavy isotopes with respect to the solar wind and other known sources. Indeed, with a low ${ }^{136} \mathrm{Xe} /{ }^{130} \mathrm{Xe}$ ratio of 1.66 , some $8 \%$ less than the solar wind, U-Xe represents an extreme end-member of postulated fractionation patterns, and has yet to be detected in the solar system.

If U-Xe is in fact a good description of Earth's primordial xenon, then it must have come from a source that was isotopically distinct from the solar nebula as a whole. It is probable that Venus also accreted its xenon from this source. In fact, the atmosphere of Venus is perhaps the one place in the solar system where one could expect to find U-Xe, as predicted by the U-Xe hypothesis (Pepin, 1991). If it turns out that U-Xe is indeed present on Venus, as signified, in particular by a ${ }^{136} \mathrm{Xe} /{ }^{130} \mathrm{Xe}$ ratio about $8 \%$ lower then in the solar wind, the implications for the accretion of solid bodies throughout the inner solar system would be profound.

To resolve these various scenarios, xenon isotopic ratio measurements of at least $5 \%$ accuracy are desired. This accuracy well resolves the $\sim 20 \%$ fractionation characteristic of terrestrial and martian xenon. To measure the difference in ${ }^{136} \mathrm{Xe} /{ }^{130} \mathrm{Xe}$ between xenon derived from hypothetical U-Xe and solar wind xenon (8\%), or to measure abundance of radiogenic ${ }^{129} \mathrm{Xe}(7 \%$ on Earth), requires a somewhat higher precision, at least $\sim 3 \%$. Fissogenic xenon is perhaps more problematic: its reported detection in Earth's atmosphere at the $4 \%$ level is model-dependent. But in principle as much as $10 \%$ of the ${ }^{136} \mathrm{Xe}$ on Venus could be fissogenic, and a measurement accuracy of $\sim 3 \%$ in the ${ }^{136} \mathrm{Xe} /{ }^{130} \mathrm{Xe}$ ratio would likely provide valuable insight.

Additional information on the source and nature of planetary material comes from the bulk ratios of various heavy noble gases. The uniform enhancement of xenon, krypton, and argon seen in Jupiter by the Galileo probe implies that "solar composition" planetesimals ("cold comets") were 
abundant in the solar system. $\mathrm{Kr} / \mathrm{Xe}$ and $\mathrm{Ar} / \mathrm{Kr}$ on Venus thus provide tests on whether these solar-like planestimals also reached Venus and contributed to the volatile inventories of the terrestrial planets. However, existing measurements of krypton on Venus differ by more than an order of magnitude (Von Zahn et al., 1983). If the lower krypton estimate is correct, then $\mathrm{Kr} / \mathrm{Xe}$ and $\mathrm{Ar} / \mathrm{Kr}$ on Venus more closely resemble the solar wind and Jupiter's atmosphere, thus strengthening the solar-like planetesimal hypothesis. If the higher estimate is correct, then the Venus $\mathrm{Ar} / \mathrm{Kr}$ ratio instead resembles a number of other objects, including meteorites, Earth, Mars, and lab measurements of gases trapped in cold ice (Notesco et al., 2003), and the $\mathrm{Kr} / \mathrm{Xe}$ ratio can then be used to discriminate between the different sources to clarify the nature and distribution of materials that formed the inner planets. Thus, determination of the bulk krypton abundance at the $5 \%$ level would provide fundamental insight into the origin of Venus, specifically providing valuable insights into the commonality of its volatile materials with other solar system objects.

Argon and Neon: Evidence for a Single Large Impact. A major discovery by the Pioneer Venus probes was that noble gases on Venus do not obey the "planetary" pattern generalized from Earth, Mars, and many meteorites. The striking result is that Venus has vastly too much neon and primordial (non-radiogenic) argon $\left({ }^{36} \mathrm{Ar}\right.$ and ${ }^{38} \mathrm{Ar}$ ), indicating an unusual source of argon not seen in the other inner planets.

There are three leading theories for the high abundance of neon and argon, two of which involve an anomalous large impact event not experienced by the other inner planets. The first hypothesis is that the solar wind implanted noble gases into meter-size particles in the neighborhood of Venus that later assembled into a large, $\mathrm{km}$-scale body that eventually struck Venus (McElroy and Prather, 1981; Wetherill, 1981). Thus the source of enhanced neon and argon is the Sun, delivered via a very large, "solar-contaminated" impactor. Sasaki (1991) showed that this model can work in the more realistic context of an optically thick, vertically extended dust disk generated by collisions between planetesimals.

A second theory holds that Venus experienced an impact of a very large, very cold comet from the outer solar system. If this comet had the same argon-rich composition of the hypothetical pollutants of Jupiter's atmosphere, it would need to have been $>\sim 200 \mathrm{~km}$ diameter to supply the enhanced argon content of Venus. Relatively recent work by Gomes et al. (2005) estimates that the late bombardment delivered $\sim 10^{23} \mathrm{~g}$ of cometary material to Earth and Venus; i.e., the mass of a dozen $200 \mathrm{~km}$ diameter comets. Thus, if such cold comets existed-and enhanced noble gas abundances on Jupiter suggest that they probably did-the Gomes et al
(2005) result implies that there is no difficulty supplying enough argon from the outer solar system.

A third theory is that argon was captured gravitationally from the solar nebula on both Venus and Earth, but survived better on Venus because this planet's thicker atmosphere provided more protection against catastrophic loss by giant impacts (Genda and Abe, 2005).

In-situ measurement of ${ }^{36} \mathrm{Ar} /{ }^{38} \mathrm{Ar}$ in Venus' atmosphere helps to distinguish between these theories by, in particular, testing whether the solar wind ratio (currently under analysis by the Genesis mission, e.g. Grimberg et al., 2007) is observed on Venus. The Pioneer Venus probes measured the ${ }^{36} \mathrm{Ar} /{ }^{38} \mathrm{Ar}$ ratio on Venus to only $10 \%$, too crude to determine if the planet's signature is that of the solar wind, based on early Genesis results. New measurements at the $1-3 \%$ level could prove valuable in separating out these scenarios once the Genesis mission results are finalized.

\section{Venus Geologic Activity Through Time: Interior Degassing Revealed by Radiogenic Argon and Helium}

On Earth the most powerful probes of mantle degassing are radiogenic argon and radiogenic and non-radiogenic helium. Venus has about $25 \%$ as much atmospheric radiogenic ${ }^{40} \mathrm{Ar}$ (from potassium, ${ }^{40} \mathrm{~K}$ decay, half-life $1.3 \mathrm{Gyr}$ ) as Earth. This strongly implies that Venus either (1) is less degassed than Earth, or (2) has significantly less potassium (Turcotte and Schubert, 1988). A plausible scenario would be a large decrease in the degassing rate of Venus one billion years or so after formation. The low ${ }^{40} \mathrm{Ar}$ abundance coupled with the very high ${ }^{36} \mathrm{Ar}$ content results in a ${ }^{40} \mathrm{Ar} /{ }^{36} \mathrm{Ar}$ ratio near unity. In contrast, the large ${ }^{40} \mathrm{Ar} /{ }^{36} \mathrm{Ar}$ ratios measured for Earth, Mars, and Titan ( 150-2000, Owen, 1992; Atreya et al., 2006a, 2006b) has been taken to indicate active geologies.

Helium (He) offers another probe of planetary degassing through time. Helium has two stable isotopes: the abundant ${ }^{4} \mathrm{He}$ and the rare ${ }^{3} \mathrm{He}$. More than $90 \%$ of the ${ }^{4} \mathrm{He}$ on Earth is radiogenic, chiefly made by the decay of uranium and thorium (with relevant half-lives of $0.7,4.5$, and 12 billion years), whilst most of the ${ }^{3} \mathrm{He}$ on Earth is primordial (i.e., non-radiogenic). On Earth the continents, which are granitic and greatly enriched in thorium and uranium, are a major source of ${ }^{4} \mathrm{He}$, while the mantle is a source of both isotopes in the ratio of 90,000:1. Degassing of ${ }^{3} \mathrm{He}$ indicates that Earth's interior still retains a noble gas imprint that dates to its formation. Similarly, measurements of ${ }^{3} \mathrm{He}$ and ${ }^{4} \mathrm{He}$ on Venus could give insight into the degree of mantle degassing and associated active geology there.

Helium escapes rapidly from Earth's atmosphere but apparently does not currently escape from Venus (Donahue and Russell, 1997). If there really has been no atmospheric 
escape, about twice as much radiogenic ${ }^{4} \mathrm{He}$ would be expected as radiogenic ${ }^{40} \mathrm{Ar}$ (assuming an Earth-like K/U ratio). What is actually observed seems to be less ${ }^{4} \mathrm{He}$. If ${ }^{4} \mathrm{He}$ escaped, then the corresponding ${ }^{3} \mathrm{He}$ escape rate should be greater, thus reducing the ${ }^{3} \mathrm{He} /{ }^{4} \mathrm{He}$ ratio. On the other hand, a high ${ }^{3} \mathrm{He} /{ }^{4} \mathrm{He}$ ratio in the current atmosphere could imply either (1) a relatively small helium escape rate (as expected, e.g., Donahue and Russell, 1997), (2) a relatively large and relatively recent degassing event from the mantle (perhaps on the time scale of water degassing events discussed below), or (3) a relatively small amount of near-surface ${ }^{4} \mathrm{He}$-producing granitic material (Turcotte and Schubert, 1988). Better information on both the escape rates and isotopic ratios of helium (the latter to a measurement accuracy of approximately 20\%) would provide new insight into the geology, outgassing history, and evolution of Venus. The Venus Express ASPERA experiment will directly measure the helium escape rates. What remains, then, is atmospheric measurements of the helium isotopic abundances, which can only be provided by in-situ observations.

\section{BEYOND NOBLE GASES: ATMOSPHERIC LOSS AND CLIMATE THROUGH TIME}

Due largely to the intense greenhouse effect, the atmosphere of Venus today is vastly different from that at Venus' formation. The large ratio of deuterated water, $\mathrm{HDO}$, relative to $\mathrm{H}_{2} \mathrm{O}$ - some 150 times that found on Earth-attests to the loss of most of Venus' water during the planet's evolution. The hypothetical sources and mechanisms responsible for the higher $\mathrm{D} / \mathrm{H}$ ratio are currently controversial and range from the loss of a primordial ocean to steady state mechanisms, wherein water supplied by cometary infall and volcanic outgassing is lost by atmospheric hydrogen escape and oxidation of Fe-bearing crustal minerals (Grinspoon, 1993). A key question is the amount of water in the past, estimated to be equivalent to a global ocean between 5 and $500 \mathrm{~m}$ in depth. The large uncertainty arises from a lack of precise measurements of the $\mathrm{D} / \mathrm{H}$ ratio, as well as uncertainties in the current loss rate of $\mathrm{H}$ and $\mathrm{O}$. Another source of uncertainty is the fractionation factor between $\mathrm{H}$ and $\mathrm{D}$ loss, and how this factor has varied with time, as differing loss processes have dominated. The $\mathrm{D} / \mathrm{H}$ ratio ranges from 0.013 to 0.025 based on $\mathrm{PVO}$ mass spectrometer and IR spectroscopy data, considering the full range of measurement uncertainties. If escape fluxes are currently in the upper end of the range suggested by current (pre-Venus Express) observations, $\approx 3 \times 10^{7} \mathrm{~cm}^{-2} \mathrm{~s}^{-1}$, then the greatly enhanced (over terrestrial) $\mathrm{D} / \mathrm{H}$ ratio must reflect loss over the last $0.5 \mathrm{Gyr}$, and would mask a primoridal signature (Grinspoon, 1993; Donahue 1999).
Additional information on atmospheric loss comes from the isotopic ratio of nitrogen, ${ }^{15} \mathrm{~N} /{ }^{14} \mathrm{~N}$. Currently this ratio $\left(3.8 \pm 0.8 \times 10^{-3}\right)$ is known to $\pm 20 \%$, at which precision the ratio is comparable to the terrestrial value $\left(3.7 \times 10^{-3}\right)$ and broadly similar to nitrogen in meteorites. However, the value is significantly different than in the atmospheres of Mars $\left(5.9 \pm 0.5 \times 10^{-3}\right)$ or Jupiter $\left(2.3 \pm 0.3 \times 10^{-3}\right)$. The usual scenario is that Earth and Mars accreted their nitrogen from a common meteoritic or chondritic source, and that heavy nitrogen on low-gravity Mars means that the light nitrogen preferentially escaped, while light nitrogen on Jupiter means that Jupiter's nitrogen was supplied by a cometary or nebular source. Because Venus has roughly the same amount of nitrogen as Earth, the expectation is that Venus accreted its nitrogen from the same common source that Earth and Mars did. Comparison of the nitrogen isotopes between Venus and Earth should help determine whether nitrogen escape was significant on at least one of the two planets. In summary, in-situ measurements of the isotopic ratios of ${ }^{15} \mathrm{~N} /{ }^{14} \mathrm{~N}$ and $\mathrm{HDO} / \mathrm{H}_{2} \mathrm{O}$ to $\sim 3 \%$ would provide data fundamental to understanding (1) present and past atmospheric loss rates, (2) the nature of the ancient climate of Venus, and (3) the role of comets in providing volatiles to the inner planets.

Among the light gases, the most important to understand from the perspective of planetary composition and accretion are the stable oxygen isotopes. Because there are three such isotopes, it is possible to distinguish fundamentally different compositions from mere isotopic fractionation. For example, the Earth and Moon share the same distinctive oxygen composition, which is is clearly distinct from those of nearly all meteorites, including the meteorites that come to us from Mars and Vesta (e.g., Stevenson, 2005). Specifically, the ${ }^{17} \mathrm{O} /{ }^{16} \mathrm{O}$ ratio of Vestan meteorites lies about $0.02 \%$ below the Earth-Moon mass-dependent fractionation line, and Mars lies $0.04 \%$ above that line. That the Earth and Moon share the same oxygen isotopes is currently viewed as a profound mystery, because according to the best available simulations of the Moon-forming impact, the Moon forms almost wholly from the planet that struck the Earth (Canup, 2004), and hence ought to be as different from Earth as Mars is.

Similar isotopic measurements of oxygen for Venus would be valuable in understanding the relationships of the materials comprising Earth, Moon, and Venus. If Venus is distinct from the Earth and Moon, we would learn that Venus accreted from a different pool of planetesimals than the Earth did. If it is the same as Earth, it would not only show Venus accreted from the same reservoir of materials as Earth, but it would also suggest that the equivalence of the Earth and Moon is not so mysterious.

To be useful, ${ }^{17} \mathrm{O} /{ }^{16} \mathrm{O}$ ratios need to be measured to significantly better than $0.01 \%$. This level of precision may be 
available with tunable laser spectroscopy techniques (e.g., Christensen et al., 2007a, 2007b) applied to isotopic carbon-dioxide. Adequate vertical sampling would be desired to effectively address issues arising from photochemical fractionations produced by atmospheric photochemistry.

\section{VENUS TODAY: UNDERSTANDING ACTIVE GEOLOGIC, CHEMICAL, AND DYNAMICAL PROCESSES}

\section{Tracers of Active Volcanism}

In-situ measurements of $\mathrm{SO}_{2}$ and OCS provide constraints on present-day volcanic activity and geologic processes. Temporal variations in atmospheric content are especially intriguing. Indeed, a global decrease in $\mathrm{SO}_{2}$ on a decadal scale was first observed in the atmosphere above the clouds by the Pioneer Venus Orbiter (Esposito, 1984). This decrease may have been due to the dissipation of a volcanic eruption of $\mathrm{SO}_{2}$ prior to the arrival of the spacecraft (ibid). Alternatively, the $\mathrm{SO}_{2}$ decrease may have been due to dynamical processes, including decadal-scale variations in the circulation within the Venus mesosphere where both $\mathrm{SO}_{2}$ and $\mathrm{CO}$ exhibit steep vertical gradients (Clancy and Muhleman, 1991; Bézard et al., 1993). More refined measurements of $\mathrm{SO}_{2}, \mathrm{CO}$, and OCS obtained in-situ lower down in the atmosphere, and with more extensive spatial and temporal coverage, would provide significantly more meaningful constraints on volcanism than previously available.

Additional information on interior degassing during recent geologic times - primarily by volcanism - are potentially provided by the isotopic ratios of other light gases, in particu$\operatorname{lar}^{33} \mathrm{~S} /{ }^{32} \mathrm{~S}$, and ${ }^{34} \mathrm{~S} /{ }^{32} \mathrm{~S}$, which are fixed in volcanic and interior processes. However, sulfur isotopes are susceptible to modifications via surface chemistry involving iron sulfides and via the atmospheric sulfur cycle, including fractionation processes involving photochemistry. Indeed, Laboratory experiments at $193 \mathrm{~nm}$ obtain anomalous fractionationsdeviations from simple mass-dependent fractionation-as large as 7\% (Farquhar et al. 2004). But in practice natural samples that have not been biologically fractionated show conventional fractionations smaller than $1 \%$ and anomalous fractionations of a few tenths of a percent at most. The biggest anomalous fractionation reported in a Martian meteorite is $0.1 \%$ (Farquhar et al., 2007).

Useful measurements of the ${ }^{34} \mathrm{~S} /{ }^{32} \mathrm{~S}$ and ${ }^{33} \mathrm{~S} /{ }^{32} \mathrm{~S}$ isotopes ratios occur about the $1 \%$ level, which would yield quantitative constraints on anomalous isotopic effects in photochemical hot spots. More realistically, $0.1 \%$ precision is needed to discriminate reaction pathways. A long-duration mobile mission (e.g. a balloon) utilizing the high-precision afforded by tunable laser spectroscopy (e.g., Christensen et al., 2007a, 2007b) would be especially useful since good characterization of sulfur isotopes requires multiple samples obtained in many environments.

Another potential tracer of volcanic activity is water and its isotope HDO. Measurement of the abundances of magmatic $\mathrm{H}_{2} \mathrm{O}$ and $\mathrm{HDO}$ released in a volcanic eruption would help to distinguish recent volcanic sources from exogenic or primordial sources, thus yielding valuable insights into the evolution of the $\mathrm{H}_{2} \mathrm{O}$-poor atmosphere and the efficacy of present theories of global tectonics, insights into the history and current rate of volcanic activity, and constraints on the oxidation rate of the crust.

\section{Chemistry, Composition, and Transport}

Venus atmospheric chemistry involves complex and varied chemical cycles $-\mathrm{H}_{2} \mathrm{SO}_{4}$ cloud formation from $\mathrm{SO}_{2}$ and $\mathrm{H}_{2} \mathrm{O}$, $\mathrm{CO}$ generated by photochemistry, $\mathrm{OCS}$ and $\mathrm{HCl}$ produced by thermochemistry, and $\mathrm{SO}_{2}, \mathrm{H}_{2} \mathrm{O}$, and $\mathrm{HCl}$ in volcanic gases (Prinn and Fegley, 1987). By influencing radiative balance, these gases and clouds play a large role in establishing and maintaining the current climate. As well, the temporal and spatial variability of $\mathrm{SO}_{2}$ and OCS give clues to the current rate of volcanic outgassing and the state of geologic activity on the planet. In addition, a fuller understanding of the radiative roles of these molecules and their connection with current and past resurfacing and outgassing would provide important clues to possible past climates on Venus.

Previous in-situ probe missions-lasting less than an hour in the atmosphere - provided sparse sampling of these important chemical constituents. The longer-lasting VEGA balloons lacked instruments capable of measuring composition. As a result, the roles of chemically-active species in maintaining radiative balance and climate, and their connection to volcanic activity, are poorly understood. A long-duration in-situ mission, perhaps balloon-borne, can make precise compositional measurements repeatedly over a range of altitudes and latitudes, to help resolve these important issues.

The Sulfur Cycle. Sulfur dioxide $\left(\mathrm{SO}_{2}\right)$ plays key roles in the planet's radiative balance, atmospheric chemistry and surface-atmosphere interactions (cf., Prinn and Fegley,1987; Moroz et al., 1990). It is the third most abundant gas below the clouds, the feedstock for the global $\mathrm{H}_{2} \mathrm{SO}_{4}$ clouds, the second most important greenhouse gas, and, as noted earlier, historically the most suspected tracer of volcanic activity. In addition, by constraining models of climate evolution, $\mathrm{SO}_{2}$ measurements provide key data for understanding the origin of the Venus greenhouse effect, with implications for understanding the future climate evolution of Earth. 
The stability of the atmosphere is intimately intertwined with $\mathrm{SO}_{2}$ and its role in the sulfur cycle. The existence of $\mathrm{H}_{2} \mathrm{SO}_{4}$ clouds and ultraviolet absorbing haze (suspected to be comprised of sulfur allotropes) are largely due to $\mathrm{SO}_{2}$ and the sulfur cycle. As part of this process, the low abundances of $\mathrm{H}_{2} \mathrm{O}$ and $\mathrm{O}_{2}$ are partly due to their removal by $\mathrm{SO}_{2}$ in the formation of $\mathrm{H}_{2} \mathrm{SO}_{4}$. The non-uniform height profile of $\mathrm{CO}$ is also due to sulfur chemistry. Simply put, oxidation of $\mathrm{SO}_{2}$ is one of the most important phenomena in the Venus atmosphere.

There are three main Venus sulfur cycles. First, the geologic cycle occurs at and below the surface, and is the ultimate source of atmospheric sulfur. Under the pressurecooker environment of the hot, $\mathrm{CO}_{2}$-laden near-surface atmosphere, $\mathrm{OCS}$ and $\mathrm{H}_{2} \mathrm{~S}$ gases are released from pyrite $\left(\mathrm{FeS}_{2}\right)$, particularly during active volcanism. Next, $10-40 \mathrm{~km}$ above the surface, the slow atmospheric cycle occurs, transforming these species into elemental and allotropic sulfur and $\mathrm{SO}_{3}$. The latter then produces a small amount of $\mathrm{H}_{2} \mathrm{SO}_{4}$, by combining with $\mathrm{H}_{2} \mathrm{O}$. The slow cycle is thought to be responsible for producing $U V$-absorbing elemental and allotropic $\mathrm{S}_{\mathrm{n}}$, the putative major UV absorber observed on Venus. In this process, OCS is converted into $\mathrm{CO}$ and $\mathrm{S}_{\mathrm{n}}$.

Finally, the fast atmospheric cycle occurs primarily above the main cloud deck, and to some extent, in the lower atmosphere, from 40 to $80 \mathrm{~km}$ altitude. This chemical cycle-also involving $\mathrm{CO}$ - utilizes photochemical as well as thermochemical reactions, and leads to the primary production of $\mathrm{SO}_{2}$ and bulk $\mathrm{H}_{2} \mathrm{SO}_{4}$ clouds on Venus.

Comprehensive, in-situ measurements of $\mathrm{SO}_{2}, \mathrm{H}_{2} \mathrm{O}$, and $\mathrm{CO}$ in the middle and upper atmosphere over an extended period and range of altitudes and latitudes, together with measurements of the mass density and abundances of $\mathrm{H}_{2} \mathrm{SO}_{4}$ particles, could lead to a new understanding of cloud formation and the variability of greenhouse gases. Together, these measurements and results would provide a fundamental key dataset for understanding thermal structure, radiative balance, chemistry, and climate on Venus.

CO: A Tracer of Atmospheric Transport. $\mathrm{CO}$ is produced by photochemistry in the upper atmosphere as well as by thermochemistry in the middle atmosphere. Previously observed spatial variations in the $\mathrm{CO}$ abundance appear indicative of global-scale dynamics (Collard et al., 1993). A 35\% CO enhancement north of $47^{\circ} \mathrm{N}$ observed by Galileo/NIMS has been attributed to concentration by the polar descending branch of an equator-to-pole cell (Taylor, 1995). In-situ measurements over a wide range of latitudes could map CO directly, providing another means to assess latitudinal and vertical circulation.

Water. Water is the third most important greenhouse gas in Venus' atmosphere, is intimately involved in forming the global $\mathrm{H}_{2} \mathrm{SO}_{4}$ clouds, and is a potential tracer of volcanism. Furthermore, the observable $\mathrm{H}_{2} \mathrm{O}$ inventory is $\sim 10^{5}$ times lower than on Earth, an important clue for understanding the different evolutionary paths of the two planets.

The VORTEX experiment on Pioneer Venus detected spatial variability of the cloud-top $\mathrm{H}_{2} \mathrm{O}$ vapor abundance (Schofield et al., 1982). On the night side, the water abundance was below the detection limit ( $6 \mathrm{ppm})$ and the equatorial midafternoon was the wettest (up to $100 \pm 40$ ppm vs. $<6-30$ ppm elsewhere). This enhancement may have been generated by vertical uplift of deeper, moister air via convection and Hadley circulation. To validate the role of water in cloud formation, search for additional evidence of volcanic activity, and refine existing theories of atmospheric evolution, in-situ missions should sample $\mathrm{H}_{2} \mathrm{O}$ over a wide range of latitudes and longitudes, to an absolute abundance accuracy of $15 \%$.

Nitrogen. $\mathrm{N}_{2}$ is the second most abundant species in the Venus atmosphere. Since the lifetime of $\mathrm{N}_{2}$ on Venus is $>100$ Myr, a uniform mixing ratio is expected. Yet, past gas chromatograph measurements by the Pioneer Venus and Venera spacecraft are surprising, suggesting a height-dependent mixing ratio. Specifically, the $\mathrm{N}_{2}$ abundance varies widely with altitude, from a low of $2.5 \%$ abundance near $22 \mathrm{~km}$ to a high of $4.6 \%$ at $52 \mathrm{~km}$ (e.g., Table V of von Zahn et al., 1983). This apparently strong altitude-dependent behavior of nitrogen implies that either the Pioneer Venus and/or Venera measurements are in error, or we do not completely understand the physico-chemical processes in the interior and atmosphere of Venus. In-situ measurements are needed to measure the $\mathrm{N}_{2}$ abundance to $5 \%$ over altitude, sufficient to determine the validity of the Pioneer Venus and Venera measurements and whether $\mathrm{N}_{2}$ is truly a well-mixed component of the Venus atmosphere.

Clouds, Meteorology, and Lightning. In-situ measurements of the spatial and temporal variability of middle-level clouds and their constituent gaseous cloud-forming material can provide quantitative constraints on cloud evolution, including the growth and dissipation rates of cloud mass densities and constituent particles. The need for such measurements was highlighted by the glimpse of Venus provided by the Galileo spacecraft enroute to Jupiter.

The Near-Infrared Mapping Spectrometer (NIMS) experiment onboard Galileo found large variations in the mean particle size of cloud particles, with marked hemispherical asymmetry (Carlson et al., 1993b; cf., Plate. 2). Particles were ten times larger by volume in the northern hemisphere. Explanations for such marked hemispherical differences in cloud particle sizes are uncertain, but likely involve spatial variations in dynamical properties such as temperature, eddy 
diffusion (turbulence), and strengths of up/downdrafts that bring cloud-forming gases (principally $\mathrm{SO}_{2}$ and $\mathrm{H}_{2} \mathrm{O}$ ) into the region. The NIMS results indicate that if cloud particle size is due to mixing of vertically stratified source regions (e.g., photochemical and condensation source mechanisms), then mixing must be coherent over very large spatial scales, in turn implying relatively small variations in small-scale dynamical regimes. Yet, the distinct regional character of particle sizes may indicate sharp regional variations in the strength of dynamical mechanisms (e.g., turbulence, up/ downwelling).

Measurements by an in-situ airborne mission can scrutinize cloud evolution in unprecedented detail. In particular, in-situ measurements of (1) cloud particle sizes, acquired simultaneously with measurements of (2) $\mathrm{H}_{2} \mathrm{O}, \mathrm{SO}_{2}$, and other species involved in the formation of $\mathrm{H}_{2} \mathrm{SO}_{4}$ clouds, can be correlated as well with (3) the measured vertical velocities and (4) temperature variations, to distinguish among mechanisms hypothesized for the distinct regional particlesize differences seen by NIMS.

Lightning — both an indicator of dynamics and an enabler of non-local thermodynamic equilibrium - was detected by the Venera 11-14 landers (Ksanfomaliti, 1979, 1983) and by Pioneer Venus (Taylor et al., 1979; Russell, 1991) as electromagnetic impulses. Venera data indicate that the rate of lightning discharges is possibly greater than on Earth (Russell, 1991). The locations of the flashes of the two optical investigations to have successfully observed lightning (Krasnopolsky, 1983; Hansell et al., 1995) are shown in Figure 1. Both plasma wave and optical observations show frequent occurrence in the dusk terminator region and on the

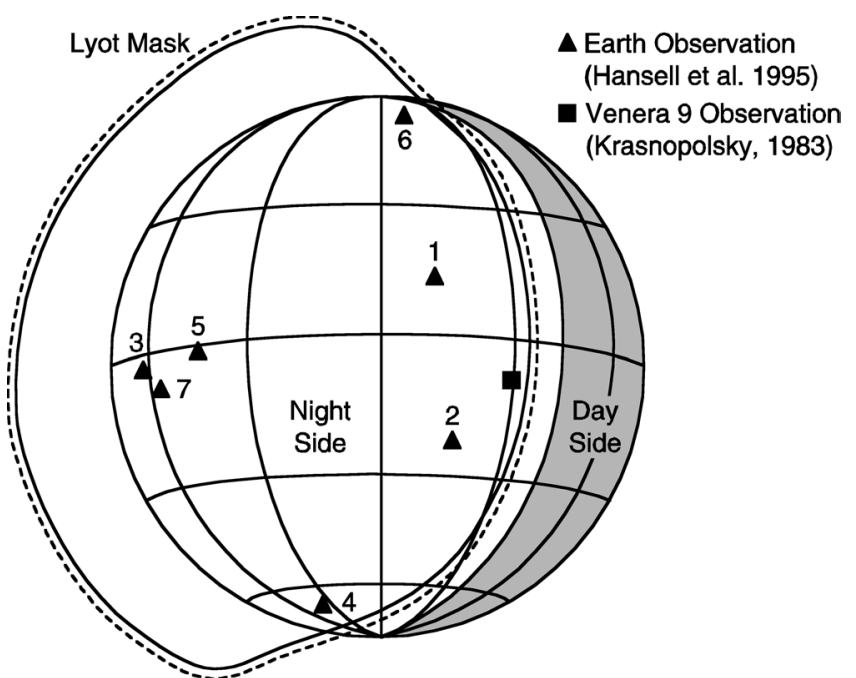

Figure 1. Locations of visible lightning flashes seen from a terrestrial telescope by Hansell et al. (1995) and from orbit by Krasnopolsky (1983). equator similar to the local time and latitudinal asymmetries in the distribution on Earth. A long-term in-situ monitor of lightning within the convective cloud layer could provide key observations of lightning frequency and strength over all local times and over a wide range of latitudes and elucidate its role in the chemistry of the Venus atmosphere. Lightning is a potentially important source of NOx compounds ( $\mathrm{NO}$, $\mathrm{NO}_{2}, \mathrm{NO}_{3}$ ) in the middle atmosphere. The existence of $\mathrm{NOx}$ species is indirect evidence for lightning, as it is the only source of $\mathrm{NO}$ in the lower atmosphere. If NOx species exist at a level of $10 \mathrm{ppb}$ or greater, they have a potentially significant impact on (a) recycling of $\mathrm{CO}_{2}$ through $\mathrm{NOx}-\mathrm{HOx}$ catalytic reactions, and (b) catalytic oxidation of $\mathrm{SO}_{2}$ to $\mathrm{H}_{2} \mathrm{SO}_{4}$. Krasnopolsky (2006) has recently reported an NO abundance of $5.5 \pm 1.5 \mathrm{ppb}$ from high-resolution spectra at $5.3 \mu \mathrm{m}$ obtained with the TEXES spectrograph at the NASA/IRTF facility on Mauna Kea, Hawaii. The results correspond to a global flash rate of $87 \mathrm{~s}^{-1}$ and $6 \mathrm{~km}^{-2} \mathrm{y}^{-1}$, if the flash energy on Venus is similar to that on Earth $\left(\sim 10^{9} \mathrm{~J}\right)$.

In-situ measurements of NO-bearing species can be used to better understand middle-cloud-level chemistry and further elucidate the importance of lightning in the Venus atmosphere. The results could be compared with measurements of lightning emission rates and strengths to further clarify the role of lightning in shaping the chemistry of the Venus atmosphere.

\section{IN-SITU EXPLORATION OF THE VENUS ATMOSPHERE: POTENTIAL MISSION ARCHITECTURES}

The Decadal Survey (NRC, 2003) and the accompanying white paper on Venus (Crisp et al., 2002) have specified the community-wide consensus of science priorities for Venus. Missions involving direct, in-situ measurements of atmospheric properties figured heavily in the recommended priorities, most notably resulting in the recommendation of a Venus atmospheric and surface sampling mission as a high-priority New Frontiers mission. Here, we briefly re-visit the Venus science objectives recommended by the Decadal Survey, with an eye to identifying the minimum mission architectures that can effectively address each objective.

Tables 1-3 list each of the science themes, questions, and priority science investigations for Venus, as determined by the Inner Planets Panel of the Decadal Survey (cf., Table 2.1 of the Decadal Survey report (NRC, 2003). Each table covers a particular Theme promoted by Decadal Survey-Venus Past, Present, and Future. We have then listed, in bold, the simplest, least-expensive, in-situ mission architectures which we deem can meaningfully achieve a significant portion of these recommended priority science investigations. Both 
Table 1. Effective Mission Architectures for Discovering Venus's Past

\begin{tabular}{|c|c|c|c|c|}
\hline Theme & Questions & Priority Science Investigations & $\begin{array}{l}\text { In-Situ Methods } \\
\text { (Simplest Mission } \\
\text { Architecture) }\end{array}$ & Orbiter Methods \\
\hline $\begin{array}{l}\text { Past: What led } \\
\text { to the unique } \\
\text { character of our } \\
\text { home planet? }\end{array}$ & $\begin{array}{l}\text { b. What is the internal } \\
\text { structure and how did } \\
\text { the core, crust, and } \\
\text { mantle of each planet } \\
\text { evolve? } \\
\text { c. What were the } \\
\text { history and role of early } \\
\text { impacts? } \\
\text { d. What is the history } \\
\text { of water and other } \\
\text { volatiles and how did } \\
\text { the atmospheres of } \\
\text { inner planets evolve? }\end{array}$ & $\begin{array}{l}\text { 1. Determine elemental and mineralogic surface } \\
\text { compositions } \\
\text { 2. Measure noble gas compositions of atmospheres } \\
\text { 3. Measure oxygen isotopic ratios of the unaltered } \\
\text { surface and atmosphere. } \\
\text { 4. Determine interior (mantle) compositions. } \\
\text { 1. Determine horizontal and vertical variations in } \\
\text { internal structures. } \\
\text { 2. Determine the compositional variations and } \\
\text { evolution of crusts and mantles } \\
\text { 3. Determine major heat-loss mechanisms and } \\
\text { resulting changes in tectonic and volcanic styles. } \\
\text { 4. Determine characteristics of Fe-rich metallic cores } \\
\text { (size, liquid and solid components). } \\
\text { 1. Determine large-impactor flux in the early solar } \\
\text { system and calibrate the lunar impact record. } \\
\text { 2. Determine the global geology of the inner planets. } \\
\text { 3. Investigate how major impacts early in a planet's } \\
\text { history can alter its evolution and orbital dynamics. } \\
\text { 1. Make high-precision measurements of noble gases } \\
\text { and light stable isotopes. } \\
\text { 2. Determine the composition of magmatic volatiles. }\end{array}$ & $\begin{array}{l}\text { Geophysical } \\
\text { Network } \\
\text { Geophysical } \\
\text { Network } \\
\text { Geophysical } \\
\text { Network } \\
\text { Geophysical } \\
\text { Network } \\
\text { Sample Return } \\
\text { Low-Alt Aerostats } \\
\text { Geophysical Network } \\
\text { Atmospheric Probe } \\
\text { Aerostats, } \\
\text { Geophysical Network }\end{array}$ & $\begin{array}{l}\text { Volcanic emissions } \\
\text { via spectra? } \\
\text { High-resolution } \\
\text { Radar? } \\
\text { High-resolution } \\
\text { Radar? } \\
\text { High-resolution } \\
\text { Radar? }\end{array}$ \\
\hline
\end{tabular}

potential cost-effective orbiter and in-situ missions are listed. Table 4 summarizes the in-situ mission architectures themselves. From top to bottom in Table 4, these missions become progressively more complex and costly as their capabilities in exploring the depths of Venus increase.

Fundamental science goals are attainable by each mission class, from $\sim \$ 450 \mathrm{M}$ Discovery-class atmospheric sampling missions to $\sim \$ 2000 \mathrm{M}$ Flagship-class, long-duration missions to the planet's lower atmosphere and surface. We note in particular that many high-priority science measurements and objectives appear attainable with low-cost, relatively low-risk Discovery-class mission architectures, including (1) simple probes similar to the Pioneer Venus vehicles, and (2) balloon missions building on the VEGA experience. Such missions can readily capitalize on recent improvements in sampling instrumentation-including light-weight gas chromatographs/mass spectrometers (GCMS) and tunable laser spectrometers - and precise interferometric radio and Doppler tracking of in-situ vehicles, to provide effective exploration of Venus at relatively low cost and low risk.

If they are to last for more than a few hours, missions to the relatively hostile lower atmosphere and surface require developments in new technologies dealing with high-temper- ature operations. The mean surface temperature of $\sim 470 \mathrm{C}$ requires either (1) the development of a full suite of electronic components and instruments able to work under these hightemperature conditions, or (2) the development of effective refrigeration techniques to preserve benign temperatures for the most sensitive systems, at least. An alternative scheme would be to develop air-borne technologies enabling frequent "bobbing" between the hostile lower atmosphere/surface and the relatively benign environs near $55 \mathrm{~km}$ altitude. This would allow rapid descents to investigate the lower atmosphere followed by quick ascents, which together limit the craft's exposure to the high-temperature environment while enabling the achievement of effective near-surface and surface science. Such technological developments seem possible in the next decade or so, but need strong financial support by the world's space agencies to achieve success.

Among the major questions about Venus listed in Tables 1-3 are ones relating to the planet's interior. Clearly, we need to do more than just explore the atmosphere if we are to understand Venus and how it evolved to its present state. A possible source of information about the interior structure of Venus would be the variations that might exist in Venus' length of day or pole position. We have already 
Table 2. Effective Mission Architectures for Discovering Venus's Present

\begin{tabular}{|c|c|c|c|c|}
\hline Theme & Questions & Priority Science Investigations & $\begin{array}{l}\text { In-Situ Methods } \\
\text { (Simplist Mission } \\
\text { Architecture) }\end{array}$ & Orbiter Methods \\
\hline \multirow[t]{3}{*}{$\begin{array}{l}\text { Present:What } \\
\text { common } \\
\text { dynamic } \\
\text { processes shape } \\
\text { Earth-like } \\
\text { planets? }\end{array}$} & $\begin{array}{l}\text { a. What processes- } \\
\text { stabilize climate? }\end{array}$ & $\begin{array}{l}\text { 1. Determine the general circulation and dynamics of } \\
\text { the inner planets' atmospheres. } \\
\text { 2. Determine the composition of the atmospheres, } \\
\text { especially trace gases and isotopes. } \\
\text { 3. Determine how sunlight, thermal radiation, and } \\
\text { clouds drive greenhouse effects. } \\
\text { 4. Determine processes and rates of surface/ } \\
\text { atmosphere interaction. }\end{array}$ & $\begin{array}{l}\text { High-Altitude } \\
\text { Aerostat } \\
\text { High-Altitude } \\
\text { Aerostat } \\
\text { High-Altitude } \\
\text { Aerostat } \\
\text { Aerostats, Lander }\end{array}$ & $\begin{array}{l}\text { Cloud tracking, } \\
\text { Thermal Mapping } \\
\text { Near-IR } \\
\text { spectroscopy } \\
\text { Visible, NIR, } \\
\text { Mid-IR } \\
\text { NIR, Volcanic } \\
\text { emissions? }\end{array}$ \\
\hline & $\begin{array}{l}\text { b. How do active } \\
\text { internal processes shape } \\
\text { the atmosphere and } \\
\text { surface environments? }\end{array}$ & $\begin{array}{l}\text { 1. Characterize current volcanic and/or tectonic } \\
\text { activity and outgassing. } \\
\text { 2. Determine absolute ages of surfaces. } \\
\text { 3. Characterize magnetic fields and relationships to } \\
\text { surface, atmosphere, and the interplanetary medium }\end{array}$ & $\begin{array}{l}\text { Aerostats? } \\
\text { Geophysical Net. } \\
\text { Sample Return } \\
\text { Geophysical Net. }\end{array}$ & $\begin{array}{l}\text { NIR spectral } \\
\text { imaging } \\
\text { Magnetospheric } \\
\text { fields and } \\
\text { particles expmts }\end{array}$ \\
\hline & $\begin{array}{l}\text { c. How do active } \\
\text { external processes } \\
\text { shape the atmosphere } \\
\text { and surface } \\
\text { environments? }\end{array}$ & $\begin{array}{l}\text { 1. Quantify processes in the uppermost atmospheres of } \\
\text { the terrestrial planets. }\end{array}$ & & $\begin{array}{l}\text { UV spectra, } \\
\text { occultations, } \\
\text { INMS }\end{array}$ \\
\hline
\end{tabular}

Table 3. Effective Mission Architectures for Discovering Venus's Future

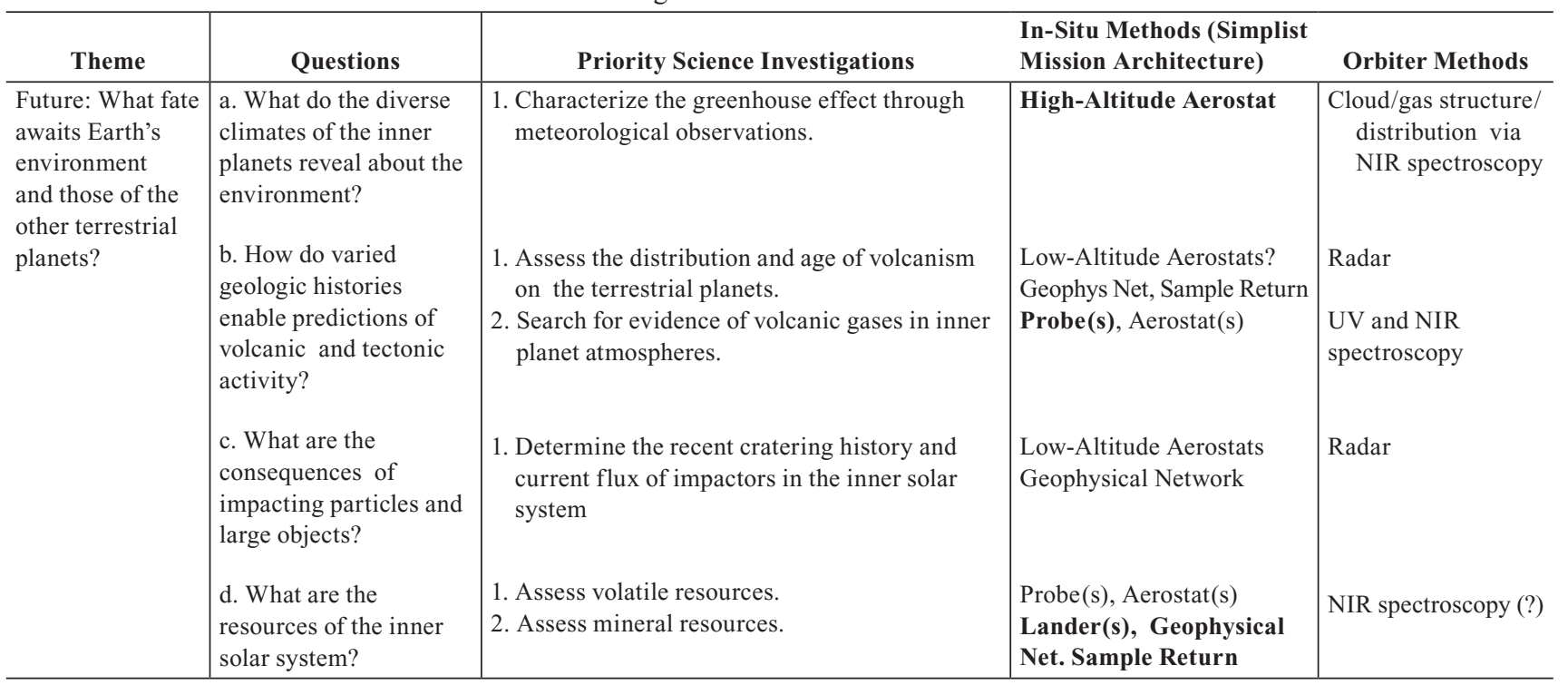

noted that length of day variations on Venus are likely due to atmosphere-solid body interactions and possibly interior processes. Whereas length of day variations on Earth are of order milliseconds, length of day variations on Venus could be of order hours (Schubert, 1983). Length of day variations on Venus are potentially observable from Earth through long term radio interferometric measurements.
The size and physical state of the core, the locations and nature of mantle phase transitions, and the thickness of the crust could be determined by a seismic/geodetic network that could directly probe the interior. Knowledge of the physical state of the core, in particular whether Venus has a solid inner core, would enable understanding of why Venus does not have an intrinsic magnetic field and how dynamos 
Table 4. Potential In-Situ Mission Architectures

\begin{tabular}{|c|c|c|c|c|c|}
\hline Mission Type & Class & $\begin{array}{l}\text { Duration } \\
\text { of Science } \\
\text { Operations }\end{array}$ & Spatial Coverage & Measurement Objectives & Instrument Technique \\
\hline $\begin{array}{l}\text { Atmospheric Probe (From } \\
100 \mathrm{~km} \text { to surface) }\end{array}$ & Discovery & $\sim 1$ hour & Single point & $\begin{array}{l}\text { Gas abundances } \\
\text { Atmospheric Structure }\end{array}$ & $\begin{array}{l}\text { GCMS, Tunable Laser } \\
\text { Spectroscopy } \\
\text { P/T measurements } \\
\text { Nephelometer } \\
\text { Accelerometer }\end{array}$ \\
\hline $\begin{array}{l}\text { High-Altitude Aerostat } \\
\qquad(\sim 56 \mathrm{~km} \text { altitude, } \sim 20 \mathrm{C})\end{array}$ & Discovery & Weeks & Hemisphere & $\begin{array}{l}\text { As above, plus: Meterology, } \\
\text { dynamics circulation, } \\
\text { volcanos }\end{array}$ & $\begin{array}{l}\text { As above, plus: Radio } \\
\text { Tracking, Doppler Tracking, } \\
\text { Pressure-level Tracking }\end{array}$ \\
\hline $\begin{array}{l}\text { Low-Altitude Aerostat ( } ~ \\
\text { km altitude, } \sim 440 \mathrm{C})\end{array}$ & $\begin{array}{l}\text { New } \\
\text { Frontiers? }\end{array}$ & Weeks & Regional & $\begin{array}{l}\text { As above, plus: Surface } \\
\text { geology, Surface } \\
\text { composition }\end{array}$ & $\begin{array}{l}\text { As above, plus: Vis-NIR } \\
\text { imager/spectroscopy, NIR } \\
\text { mapping spectrometer }\end{array}$ \\
\hline Lander & New Frontiers & $\sim 3$ hours & Single point & $\begin{array}{l}\text { As for Probe, plus: } \\
\text { Elemental geochemistry } \\
\text { Surface composition }\end{array}$ & $\begin{array}{l}\text { As for Probe, plus:XRD, } \\
\text { GRS, LASAR Ablation } \\
\text { Spectroscopy, NIR } \\
\text { mapping spectrometer, } \\
\text { Imaging microscope }\end{array}$ \\
\hline Surface Station & Flagship & Weeks & Single point & $\begin{array}{l}\text { As for Lander, plus: } \\
\text { Seismometry Core } \\
\text { sampling Surface } \\
\text { Meteorology }\end{array}$ & $\begin{array}{l}\text { As for Lander, plus: } \\
\text { Seismometer, Surface } \\
\text { Wind Monitor }\end{array}$ \\
\hline $\begin{array}{l}\text { Geophysical Network } \\
\text { (Multiple Surface } \\
\text { Stations) }\end{array}$ & Flagship & Weeks & Near global & $\begin{array}{l}\text { As for Surface Station, plus: } \\
\text { High-Res Seismometry }\end{array}$ & Same as for Surface Station \\
\hline $\begin{array}{l}\text { Sample Return (Lander } \\
\quad+\text { Aerostat + Return } \\
\text { Capsule) }\end{array}$ & Flagship + & $\sim 3$ hours & Single poin & $\begin{array}{l}\text { As for Lander and Low- } \\
\text { Altitude Aerostat, } \\
\text { plus: Detailed surface } \\
\text { mineralogy and } \\
\text { geological and planetary } \\
\text { evolution }\end{array}$ & $\begin{array}{l}\text { Same as for Lander and } \\
\text { Low-Altitude Aerostat }\end{array}$ \\
\hline
\end{tabular}

work. A geophysical network could provide measurements of the surface heat flow, an important indicator of the thermal state of the interior and the planet's complement of radiogenic elements. More information about the variations in composition and mineralogy of the surface rocks by remote sensing or in situ sampling or sample return to Earth or an orbiting spacecraft laboratory would clarify how differentiation has produced the Venusian crust and if there are fundamental compositional differences between the crusts of the volcanic and plateau highlands similar to the differences between oceanic and continental crusts on Earth. Finally, the radiogenic element content of surface rocks provides important constraints on Venus' thermal state and evolution.

Acknowledgments. We wish to thank David J. Stevenson for valuable comments and suggestions. Much of the work described in this paper was carried out at the Jet Propulsion Laboratory, Pasadena, CA, under contract with the National Aeronautics and
Space Administration. Funding for KHB, SKA, RWC, DC, DG and CTR was largely provided by NASA for their participation in support of ESA's Venus Express Mission.

\section{REFERENCES}

Allen, D.A., and Crawford, J.W., (1984). Cloud structure on the dark side of Venus. Nature 307, 222-224.

Atreya, S. K., Mahaffy, P. R., and Wong, A-S (2006a). Methane and related trace species on Mars: Origin, loss, implications for life, and habitability. Planet. Space Sci., in press.

Atreya, S. K., Adams, E. Y., Niemann, H. B., Demick-Montelara, J. E., Owen, T. C., Fulchignoni, M., Ferri, F., and Wilson, E. (2006b). Titan's methane cycle. Planet. Space Sci. 54, 1177-1187.

Baines, K. H., Bellucci, G., Bibring, J.-P., Brown, R. H., Buratti, B. J., Bussoletti, E., Capaccioni, F., Cerroni, P., Clark, R. N., Cruikshank, D. P., Drossart, P., et al. (2000). Detection of submicron radiation from the surface of Venus by Cassini/VIMS. Icarus 148, 307-311. 
Baines, K. H. Atreya, S., Carlson, R. W., Crisp, D., Drossart, P., Formisano, V., Limaye, S. S., Markiewicz, W. J., and Piccioni, G. (2006). To the depths of Venus: Exploring the deep atmosphere and surface of our sister world with Venus Express. Planetary and Space Sci. 54, 1263-1278.

Basilevsky, A. T., Schaber, G. G., Strom, R. G. (1997). The resurfacing history of Venus, in Venus II. Edited by S. Bougher, W., Hunten, D. M., and Philips,R.J.. Tucson, AZ : University of Arizona Press, pp.1047-1084.

Bézard, B., de Bergh, C., Fegley, B., Maillard, J. P., Crisp, D., Owen, T., Pollack, J. B., and Grinspoon, D. (1993). The abundance of sulfur dioxide below the clouds of Venus. Geophys. Res. Lett., 20, 1587-1590.

Canup R.M. (2004). Simulations of a late lunar-forming impact. Icarus 168, 433-456.

Carlson, R. W., Baines, K. H., Encrenaz, Th., Taylor, F. W., Drossart, P., L., Kamp, L. W., Pollack, J. B., Lellouch, E., Collard, A. D., Calcutt, S. B., et al. (1991). Galileo infrared imaging spectroscopy measurements at Venus. Science 253, 1541-1548.

Carlson, R.W., Baines, K.H., Girard, M.A., Kamp, L.W., Drossart, P.,Encrenaz, Th., and Taylor, F.W. (1993a). Galileo/NIMS near-infrared thermal imagery of the surface of Venus. Proc. of XXIV LPSC. p. 253.

Carlson, R. W., Kamp, L. W., Baines, K. H., Pollack, J. B., Grinspoon, D. H., Encrenaz, Th., Drossart, P., and Taylor, F. W. (1993b). Variations in Venus cloud particle properties: A new view of Venus's cloud morphology as observed by the Galileo Near-Infrared Mapping Spectrometer. Planetary and Space Science 41, 477-485.

Christensen, L. E., Brunner, B., Truong, K. N., Mielke, R. E., Webster, C. R., and Coleman, M. (2007a). Measurement of sulfur isotope compositions by tunable laser spectroscopy of $\mathrm{SO}_{2}$. Analytical Chem., in press.

Christensen. L. E., Webster, C. R., and Yang, R. Q. (2007b). Aircraft and balloon in situ measurements of methane and hydrochloric acid using interband cascade lasers, Applied Optics 46, No. 7, 1132-1138.

Clancy, R.T. and Muhleman , D. O. (1991). Long term (1979-1990) changes in the thermal, dynamical, and compositional structure of the Venus mesosphere as inferred from microwave spectral line observations of $\mathrm{C}_{12} \mathrm{O}, \mathrm{C}_{13} \mathrm{O}$, and $\mathrm{CO}_{18}$. Icarus 89, 129-146.

Collard, A. D., Taylor, F. W., Calcutt, S. B., Carlson, R. W., Kamp, L. W., Baines, K. H., Encrenaz, Th., Drossart, P., Lellouch, E., and Bézard, B. (1993). Latitudinal distribution of carbon monoxide in the deep atmosphere of Venus. Planetary and Space Science 41, 487-494.

Crisp, D., Allen, M. A., Anicich, V. G., Arvidson, R. E., Atreya, S. K., Baines, K. H., Banerdt, W. B., Bjoraker, G. L. Bougher, S. W., Campbell, B. A., Carlson, R. W., et al. (2002). Divergent evolution among Earth-like planets: The case for Venus exploration. In The Future of Solar System Exploration, 2003-2013 (M. Sykes, Ed.). ASP Conference Series, pp. 5-34.

Dobrovolskis, A. R. and Ingersoll, A. P. (1980). Atmospheric tides and the rotation of Venus. I.Tidal theory and the balance of torques. Icarus $\mathbf{4 1}, 1-17$.
Donahue, T. M., and Russell, C. T. (1997). The Venus atmosphere and ionosphere and their interaction with the solar wind: An overview. In Venus II (S. W. Bougher, D. M. Hunten, and R. Phillips, Eds.), Univ. of Arizona Press, Tucson. pp. 3-31.

Donahue, T.M. (1999). New analysis of hydrogen and deuterium escape from Venus. Icarus 141, 226-235.

Esposito, L. W. (1984). Sulfur dioxide: Episodic injection shows evidence for active Venus volcanism. Science 223, 1072-1074.

Farquhar, J., Kim, S.-T., Masterson, A. (2007). Sulfur isotope analysis of the Nakhla meteorite: Implications for the origin of sulfate and the processing of sulfur in the meteorite parent. LPSC XXXVIII, Contribution No. 1338

Farquhar, J., Johnston, D.T., Calvin, C., Condie, K. (2004). Implications of Sulfur Isotopes for the Evolution of Atmospheric Oxygen. LPSC XXXV, Contribution No. 1920.

Fegley, B. Jr. (2004). Venus, in Treatise on Geochemistry, Volume 1 (A. M. Davis, ed.), Elsevier Press.

Gelman, B. G., Zolotukhin, V. G., Lamanov, N. I., Levchuk, B. V., Muhkin, L. M., Nenarokov, D. F., Okhothikov, B. P., Rotin, V. A., and Lipatov, A. N. (1979). Gaschromatographical analysis of chemical composition of the atmosphere of Venus done by the Venera 12 probes. Plasma Astron. Zh. 5:217; NASA Tech. Mem. TM-75476.

Genda, H., and Abe, Y. (2005). Enhanced atmospheric loss on protoplanets at the giant impact phase in the presence of oceans. Nature 433, 842-844.

Gold, T. and Soter, S. (1969). Atmospheric tides and the resonant rotation of Venus. Icarus 11, 356-366.

Gold, T. and Soter, S. (1979). Theory of Earth-synchronus rotation of Venus. Nature 277, 280-281.

Gomes, R., Levison, H., Tsiganis, K., Morbidelli, A. (2005). Origin of the cataclysmic Late Heavy Bombardment period of the terrestrial planets. Nature 435, 466-469.

Grimberg, A., Baur, Burnett, D. S., H., Bochsler, P., and Wieler, R. (2007). The depth distribution of neon and argon in the bulk metallic glass flown on Genesis. Lunar and Planetary Sci. Conf. XXXVIII, \#1270.

Grimm, R. E. and Phillips, R. J. (1992). Anatomy of a Venusian hot-spot-Geology, gravity, and mantle dynamics of Eistla Regio. J. Geophys. Res. -Planets 97, E10, 16035-16054.

Grinspoon, D. H. (1993). Implications of the high D/H ratio for the sources of water in Venus' atmosphere. Nature 363, 428-431.

Hansell, S. A., Wells, W. K., and Hunten, D. M. (1995).Optical detection of lightning on Venus. Icarus 117, 345-351.

Hashimoto, G. L., and T. Imamura, T. (2001). Elucidating the rate of volcanism on Venus: Detection of lava eruptions using nearinfrared observations. Icarus 154, 239-243.

Hashimoto, G. L. and Sugita, S. (2003). On observing the compositional variability of the surface of Venus using nightside near-infrared thermal radiation. JGR-Planets 108 (E9), 5109, doi:10.1029/2003JE002082.

Herrick, R. R., Sharpton, V. L., Malin, M. C., Lyons, S. N., and Feely, K. (1997). Morphology and morphometry of impact craters, in Venus II . Edited by Stephen W. Bougher, D.M. Hunten, and R.J. Philips. Tucson, AZ : University of Arizona Press. pp.1015-1046. 
Hunten, D. M., Pepin, R. O., and Walker, J. C. G. (1987). Mass fractionation in hydrodynamic escape. Icarus 69, 532-549.

Ingersoll, A. P. and Dobrovolskis, A. R. (1978). Venus rotation and atmospheric tides. Nature 275, 37-38.

Kaula, W. M. and Phillips, R. J (1981). Quantitative Tests for platetectonics on Venus. Geophys. Res. Letters 8, 1187-1190.

Kaula, William M., Owen, T., Runcorn, S. K., Tozer, D. C. (1994). The Tectonics of Venus and Discussion. Philosophical Transactions: Physical Sciences and Engineering. 349, 345-355.

Kaula, William M., Lenardic, A., Bindschadler, D. L., and ArkaniHamed, J. (1997) Ishtar Terra, in Venus II, S. W. Bougher, D. M. Hunten, and R. J. Phillips, editors, The University of Arizona Press, pp 879- 900

Konopliv, A. S. and Yoder, C. F. (1996). Venusian k(2) tidal Love number from Magellan and PVO tracking data. Geophys. Res. Letters 23, 1857-1860

Krasnopolsky, V. A. (1983). Lightning on Venus according to information obtained by the satellites Venera 9 and 10. Kosmich. Issled. 18, 429-434.

Krasnopolsky, V. A. (2006). A sensitive search fro nitric oxide in the lower atmospheres of Venus and Mars: Detection on Venus and upper limits for Mars. Icarus 182, 80-91.

Ksanfomaliti, L. V. (1979). Lightning in the cloud layers of Venus. Kosmich. Issled. 17, 747-762.

Ksanfomaliti, L. V. (1983). Electrical activity in the atmosphere of Venus. I. Measurements on descending probes. Kosmich. Issled. 21, 279-296.

Kundt, W. (1977). Spin and atmospheric tides of Venus. Astron. Astrophysics. 60, 85-91.

Lecacheux, J., Drossart, P., Laques, P., Deladierre, F. and Colas, F. (1993). Detection of the surface of Venus at $1.0 \mathrm{um}$ from gropund-based observations. Planet.Space Sci. 41, 543-549.

Meadows, V. S. and Crisp, D. (1996). Ground-based near-infrared observations of the Venus nightside: The thermal structure and water abundance near the surface. J. Geophys. Res. 101, 4595-4622.

McElroy, M. B. and Prather, M. J. (1981). Noble gases in the terrestrial planets. Nature 293, 535-539.

McKenzie, D. Ford, P. G. Johnson, C., Parsons, B., Sandwell, D., Saunders, S., and Solomon, S. C. (1992). Features on Venus generated by plate boundary processes. J. Geophys. Res.-Planets 97, E8, 13533-13544.

McKinnon, W. B., Zahnle, K. J., Ivanov, B. A., Melosh, H. J. (1997). Cratering on Venus: Models and Observations, , in Venus II. Edited by S. W. Bougher, D.M. Hunten, and R.J. Philips. Tucson, AZ : University of Arizona Press, pp. 969- 1014.

Moroz, V. I. et al., (1990). Water vapor and sulfur dioxide abundances at the Venus cloud tops from the VENERA 15 infrared spectrometry data. Adv. Space Res 10: 77.

National Research Council (NRC) of the National Academies, Solar System Survey Space Studies Board (2003). New Frontiers in the Solar System: An Integrated Exploration Strategy. The National Academies Press. Washington, DC.

Nimmo, F. (2002). Why does Venus lack a magnetic field?, Geology 30, 987-990.
Nimmo, F. and Stevenson, D. J. (2000) Influence of early plate tectonics on the thermal evolution and magnetic field of Mars, J. Geophys. Res. 105, 11,969-11,979.

Notesco, G., Bar-Nun, A., and Owen, T. (2003). Gas trapping in water ice at very low deposition rates and implications for comets. Icarus 162, 183-189.

Owen, T. C. (1992). The composition and early history of the atmosphere of Mars. In Mars (ed., H. Kieffer, et al.). Univ. of Arizona Press, pp.818.

Ozima , M. and Podosek, F. A. (2002). Noble Gas Geochemistry, Cambridge University Press, New York.

Pepin, R. O. (1991). On the origin and early evolution of terrestrial planet atmospheres and meteoritic volatiles. Icarus 92, 2-79.

Pepin, R. O. (1997). Evolution of the Earth's noble gases: Consequences of assuming hydrodynamic loss driven by giant impact. Icarus 126, 148-156.

Phillips, J. L., and Russell, C. T. (1987). Upper limits on the intrinsic magnetic field of Venus. J. Geophys. Res. -Space Phys 92, 2253-2263.

Prinn, R.G., and Fegley, B. (1987). The atmospheres of Venus ,Earth and Mars - a critical comparison. Ann. Rev. Earth and Planet. Sci., 15, 171-212, 1987.

Porcelli, D., and Pepin, R. O. (2000).Rare gas constraints on early Earth history. In Origin of Earth and Moon, eds. R. M. Canup and K. Righter. University of Arizona Press, Tucson. pp. 435-458,

Russell, C. T. (1991). Venus lightning. Space Sci Rev 55, 317 356.

Russell, C. T. (1980). Planetary magnetism. Reviews of Geophysics. 18, 77-106.

Sandwell, D. T., and Schubert, G.(1992a). Flexural ridges, trenches, and outer rises around coronae on Venus. J. Geophys. Res.-Planets. 97, E10,16069-16083.

Sandwell, D. T. and Schubert, G. (1992b). Evidence for retrograde lithospheric subduction on Venus. Science 257, 766-770.

Sasaki, S. (1991). Off-disk penetration of ancient solar wind. Icarus 91, 29-38

Sasaki, S. and Nakazawa, K. (1988). Origin of isotopic fractionation of terrestrial Xe: Hydrodynamic fractionation during escape of the primordial $\mathrm{H}_{2}-\mathrm{He}$ atmosphere. Earth Planet. Sci. Lett. 89, 323-334.

Schaber, G. G., Strom, R. G., Moore, H. J.,Soderblom, L. A., Kirk, R. L., Chadwick, D. J. Dawson, D. D., Gaddis, L. R., Boyce, J. M., Russell, J., and Schaber, G. (1992). Geology and distribution of impact craters on Venus - What are they telling us? J. of Geophy. Res.-Planets 97, E8, 13257-13301

Schofield,J. T., Taylor, F. W., and McCleese, D. J. (1982). The global distribution of water vapor in the middle atmosphere of Venus. Icarus 52, 263-278.

Schubert, G. (1983). General Circulation and the Dynamical State of the Venus Atmosphere, in Venus, Edited by D. M. Hunten, L. Colin, T. M. Donahue, and V. I. Moroz, Tucson, AZ: The University of Arizona Press, pp. 681-765.

Schubert, G., Solomatov, V. S., Tackley, P. J., and Turcotte, D. L. (1997). Mantle convection and the thermal evolution of Venus, in 
Venus II. Edited by S. W. Bougher, D.M. Hunten, and R.J. Philips. Tucson, AZ : University of Arizona Press, pp.1245- 1287.

Seiff, A. (1983). Thermal structure of the atmosphere of Venus, in Venus, eds. D. M. Hunten, L. Colin, T. M. Donahue, and V. I Moroz, (Tucson: Univ. Arizona Press) pp. 154-158.

Senske, D. A., Schaber, G. G., and Stofan, E. R. ( 1992). Regional topographic rises on Venus-Geology of Western Eistla Regio and comparison to Beta-Regio and Atla-Regio. J. Geophys. Res.Planets 97, E8, 13395-13420.

Sjogren, W. L., W. B. Banerdt, P. W. Chodas, A. S. Konopliv, G. Balmino, J. P. Barriot, J. Arkani-Hamed, T. R. Colvin, and M. E. Davies (1997) The Venus gravity field and other geodetic parameters, in Venus II, S. W. Bougher, D. M. Hunten, and R. J. Phillips, editors, The University of Arizona Press, Tucson, pp 1125-1161.

Stevenson, D. J. (2005). The oxygen isotope similarity between the Earth and Moon-Source region or formation process? Lunar and Planetary Sci. Conf. XXXVI, \#2382.

Stevenson, D. J. (2006) Evolution of Venus: Initial conditions, internal dynamics and rotational state. Paper presented at the AGU Chapman Conference on Exploring Venus as a Terrestrial Planet, Key Largo, Florida, 13-16 February, 2006.

Stevenson, D. J., Spohn, T., Schubert, G. (1983). Magnetism and thermal evolution of the terrestrial planets. Icarus 54, 466489.

Taylor, F. W. (1995). Carbon monoxide in the deep atmosphere of Venus. Adv. Space Res. 16, (6 81-88.

Taylor, W. W. L., Scarf, F. L., Russell, C. T., and Brace, L. H. (1979). Evidence for lightning on Venus. Nature 282, 614-616.

Taylor, F. W. (2006). Venus before Venus Express. Planetary and Space Sci. 54, 1249-1262.

Titov, D. V., Svedhem, H., Koschny, D., Hoofs, R., Barabash, S., Bertaux, J. -L., Drossart, P., Formisano, V., Häusler, B., Korablev, O., Markiewicz, W. J., Nevejans, D., Pätzold, M., Piccioni, G., Zhang, T. L., Merritt, D., Witassee, O., Zender,
J., Accomazzo, A., Sweeney, M., Trillard, D., Janvier, M., and Clochet, A. (2006) Venus Express science planning. Planetary and Space Sci. 54, 1279-1297.

Turcotte, D. ( 1993) An episodic hypothesis for Venusian tectonics. J. Geophys. Res.-Planets 98, E9, 17061-17068.

Turcotte, D. L. and Schubert, G. (1988). Tectonic implications of radiogenic noble gases in planetary atmospheres Icarus 74, 36-46.

Von Zahn, U., Komer, S., Wiemann, H., and Prinn, R. (1983). Composition of the Venus atmosphere. In Venus (D. M. Hunten, L. Collin, T. M. Donahue, and V. I. Moroz, Eds.), Univ. of Arizona Press, Tucson. pp. 297-430.

Wetherill, G. W. (1981). Solar wind origin of ${ }^{36} \mathrm{Ar}$ on Venus. Icarus 46, 70-80.

Yoder, C.F. (1997).Venusian Spin Dynamics, in Venus II . Edited by Stephen W. Bougher, D.M. Hunten, and R.J. Philips. Tucson, AZ : University of Arizona Press, pp. 1087-1124.

Yoder, C. F. and Russell, C. T. (1997). The Venus atmosphere and ionosphere and their interaction with the solar wind: An overview, in Venus II. Edited by S. W. Bougher, D.M. Hunten, and R.J. Philips. Tucson, AZ, University of Arizona Press., p.1087.

Zahnle K. and Kasting, J. F. (1986). Mass fractionation during transonic escape and implications for loss of water from Mars and Venus. Icarus 68, 462-480.

Zahnle, K., Kasting, J., and Pollack, J. (1990a). Mass fractionation of noble gases in diffusion-limited hydrodynamic hydrogen escape. Icarus 84, 502-527.

Zahnle, K., Pollack, J. B., and Kasting, J. F. (1990b). Xenon fractionation in porous planetesimals. Geochimica et Cosmochimica Acta 54, 2577-2586.

Kevin H. Baines, Jet Propulsion Laboratory, California Institute of Technology, M/S 183-601, 4800 Oak Grove Drive, Pasadena, California 91109, Ph: (818) 354-0481, FAX: (818) 393-5148, Email: kbaines@aloha.jpl.nasa.gov. 
